Louisiana State University

LSU Digital Commons

\title{
The Role of Expectancy, Amnesia, and Hypnotic Induction in the Performance of Posthypnotic Behavior.
}

Ronald Lawrence Gandolfo

Louisiana State University and Agricultural \& Mechanical College

Follow this and additional works at: https://digitalcommons.Isu.edu/gradschool_disstheses

\section{Recommended Citation}

Gandolfo, Ronald Lawrence, "The Role of Expectancy, Amnesia, and Hypnotic Induction in the Performance of Posthypnotic Behavior." (1970). LSU Historical Dissertations and Theses. 1848.

https://digitalcommons.Isu.edu/gradschool_disstheses/1848

This Dissertation is brought to you for free and open access by the Graduate School at LSU Digital Commons. It has been accepted for inclusion in LSU Historical Dissertations and Theses by an authorized administrator of LSU Digital Commons. For more information, please contact gradetd@lsu.edu. 
$71-6568$

GANDOLFO, Ronald Lawrence, 1942-

THE ROLE OF EXPECTANCY, AMNESIA, AND HYPNOTIC

INDUCTION IN THE PERFORMANCE OF POSTHYPNOTIC

BEHAVIOR.

The Louisiana State University and Agricultural and Mechanical College, Ph.D., 1970

Psychology, clinical

University Microfilms, Inc., Ann Arbor, Michigan 
THE ROLE OF EXPECTANCY, AMNESIA, AND HYPNOTIC INDUCTION IN THE PERFORMANCE OF POSTHYPNOTIC BEHAVIOR

A Dissertation

Submitted to the Graduate Faculty of the Louisiana State University and Agricultural and Mechanical College

in partial fulfillment of the requirements for the degree of Doctor of Philosophy

in

The Department of Psychology

by

Ronald Lawrence Gandolfo

M.A., Louisiana State University, 1967

August, 1970 


\section{ACKNOWLEDGEMENT}

The author is indebted to Dr. Joseph G. Dawson who lent time and invaluable advice, and who patient $1 \mathrm{y}$ and critically read the drafts of this manuscript. Thanks also go to Drs. William Haag, Perry Prestholdt, Bill Seay, and Laurence Siegel for serving on my doctoral committee and for their suggestions.

Appreciation is extended to the members of the Psychology 250 class who graciously consented to train subjects for this study over a number of evenings. Deepest gratitude is reserved for my wife, Ruth, who served as co-experimenter, and who spent many hours typing drafts of this dissertation with little complaint. Finally, I appreciate the expert typing job done by Mrs. Mary Mevers, who prepared the final form of the manuscript. 
TABLE OF CONTENTS

Page

TITLE PAGE ........................... . i

ACKNOWLEDGEMENT. . . . . . . . . . . . . . . . . . . ii

LIST OF TABLES . . . . . . . . . . . . . . . . . . iv

LIST OF FIGURES. . . . . . . . . . . . . . . . . . . . v v

ABSTRACT . . . . . . . . . . . . . . . . . . . . vi v

INTRODUCTION . . . . . . . . . . . . . . . . . . 1

METHOD ........................... 32

RESULTS. . . . . . . . . . . . . . . . . 37

DISCUSSION . . . . . . . . . . . . . . . . . 。 . . 44

SUMMARY. . . . . . . . . . . . . . . . . . . 51

REFERENCES . . . . . . . . . . . . 。 . . 。 . . 52

APPENDIX A

Subject Screening Instruments... . . . . . . . . 60 APPENDIX B

Pre-traice-induction Instructions. . . . . . . . . . 65 APPENDIX C

The Posthypnotic Suggestion. . . . . . . . . . . . . 70 VITA ...........................73 73 
Table

Page

1. Analysis of Variance Design with Cel1 Means and Overall Means of Posthypnotic Scores. . . . . . . 38

2. Analysis of Variance. . . . . . . . . . . . 39

3. Significance of Differences between any Two P-S Conditions for Each I-E Condition . . . . . . . 40

4. Significance of Differences between any Two I-E Conditions for Each P-S Condition . . . . . . . 
LIST OF FIGURES

Figure

Page

1. P-S Ss' Mean Posthypnotic Scores on the Digit Symbol

Test over I-E Conditions. . . . . . . . . . .

2. I-E $\underline{S} s^{\prime}$ Mean Posthypnotic Scores on the Digit Symbo1

Test over P-S Conditions. . . . . . . . . . . . 


\begin{abstract}
The present study sought to determine the role of expectation, amnesia, and hypnotic induction in the performance of posthypnotic

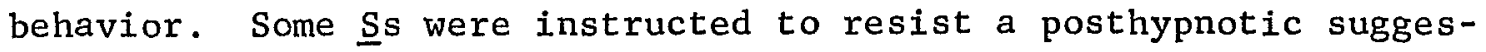
tion along with either a positive or negative expectation that they would be successful in resisting the suggestion. Other $\underline{\text { Ss were not }}$ given any instructions or expectations regarding the posthypnotic suggestion. Ss were given the suggestion either immediately before or after a hypnotic induction. Ss given the suggestion during hypnosis also differed as to whether or not they reported amnesia for it. Ss' responses to the suggestion were largely determined by what expectations they had regarding their ability or inability to resist the suggestion. Ss reporting amnesia were more responsive to the suggestion. Whether or not $\underline{S}$ seceived the suggestion during trance appeared to be of little importance. $\underline{S} s^{\prime}$ responsiveness to suggestions was explained in terms of role enactment.
\end{abstract}




\title{
INTRODUCTION
}

\author{
Historica 1 Overview \\ Pattie (1967) traced the history of hypnotism from the time
} of Mesmer. In Vienna, in 1774, Franz Anton Mesmer successfu11y treated a woman that he diagnosed as hysterical by attaching magnets to her body. He believed that magnets could cure disease by bringing a patient's confused nervous fluids into balance, thereby producing harmony among the nerves. He called this process animal magnetism which became popularly known as mesmerism. He believed that he had discovered a cosmic force that pervaded the universe and influenced the motions and equilibrium of planets as well as the nervous system of man. Mesmer soon learned that he could produce the same effects in his patients without the use of magnets. Physicians in Vienna became disenchanted with Mesmer's ideas ānd practices which led him to move to Paris in 1778. Mesmer continued to demonstrate his technique in France, hoping that he would eventually win scientific acceptance of mesmerism. However, in 1784, a medical commission appointed by the King of France investigated mesmerism and concluded that animal magnetism produced only those effects that a subject expected. They said that the phenomena were due to "imagination," and thus excluded the subject from scientific respectability.

In 1784 Mesmer founded a number of societies for the introduction of his system. One of the most important of these was a 
society in Strasbourg which was led by the Marquis de Puysegur, and which had an enrollment of around 200 students. Puysegur kept his patients in a calm frame of mind, whereas Mesmer had always induced initial convulsions in his patients by use of his method. Puysegur found that it was not necessary to excite the patient, and discovered the sleeping trance or "induced comnambulism." He also noticed that patients' reported amnesia for activities that occurred during the trance state. Puysegur was the first person to attribute the power of the magnetizer to the magnetizer's own will, rather than to some outside cosmic force.

A Portuguese priest, Jose Custodio Faria, who had received instructions from Puysegur, was the first practitioner of animal magnetism to state a psychological theory of somnambulism in which the characteristics of the subject, rather than those of the magnetizer, were made responsible for the phenomena. He described as a chief characteristic of the predisposed somnambulist that of "psychic impressionability" (suggestibility). He concluded that the comnambulistic or trance state was immediately caused by the subject "withdrawing from his senses," and by concentrating on his thoughts. He considered somnambulism and natural sleep to be the same.

Animal magnetism was being used by some physicians, especially as a means of inducing anesthesia for patients. In 1830, animal magnetism received official recognition as a medical practice when the French Academy of Medicine condoned its use.

It was also in the $1830^{\prime}$ 's that interest in animal magnetism 
developed in England. John E11iotson was the first physician of prominence to practice mesmerism in England. The support he publicly lent to mesmerism cost him dearly, both professionally and financially. His endorsement managed to bring the subject to the attention of other physicians:

James Braid, a Scottish physician, began using the technique in his practice, and won professional support because of his conservative claims for the technique and his initial "scientific" physiological explanation of the phenomena. He proposed a new name "neurohypnotism" (nervous sleep) for the phenomena, which was soon shortened to "hypnotism." His physiological explanation was changed to the psychological proposition that in hypnotism the subject was responding to suggestion in a state of mental concentration or attention to dominant ideas. The condition was not the same as sleep. The work of Braid stimulated a short lived wave of interest in using hypnosis to induce anesthesia in subjects for surgical operations. James Esdaile, a Scottish surgeon working in India, compiled an unequaled record in the use of hypnosis in surgery. He used the technique in over 1000 minor and over 300 major operations! In the late 1840's, the discovery of chemical anesthesia largely replaced hypnotism in the surgery room. In 1878, Jean-Martin Charcot, a leading and famous neurologist of the School of Salpetriere in France, began using hypnosis on women he diagnosed as hysterical. Charcot's interest in the subject made it respectable. However, he saw hypnotism as a peculiar, pathological condition connected with what he called hysteria. Hippolyte Bernheim, 
of the Nancy School in France, opposed Charcot's ideas and characterized the hypnotic state as being natural, and attributed its effects to suggestion.

Sigmund Freud became interested in the subject and observed the work of Bernheim. Early in his medical practice Freud used hypnotism to remove symptoms, and to investigate the history of his patients. He fina11y abandoned the method because the cures effected by the technique were only temporary and because a11 his patients were not good hypnotic subjects.

In the United States, the most important pioneer worker in hypnosis was Morton Prince in the early 1900's. He saw the hypnotic state as primarily dissociated from the normal waking state and emphasized changes of personality that occurred in hypnosis. It was Clark Hull, who around the same time, began to investigate hypnosis in controlled experimental study, and who initiated laboratory research into its characteristics in the United States.

\section{Theoretica1 Conceptions of Hypnosis}

There were two general contemporary viewpoints regarding hypnosis which may be referred to as a "state" view and a "skeptical" view. The state view asserted that hypnotic induction resulted in a trance state that is qualitatively different from the person's normal, waking state. The skeptical view regarded hypnotic behavior following trance induction as being no different than what a person can experience normal1y. Irance induction procedures were seen as unnecessary in eliciting what is called hypnotic behavior. This view did not discount 
the reality of hypnoticlike phenomena, but rather denied the need to invoke the concept of a "state" to explain them. A brief look at the major and representative formulations of hypnosis will elucidate the different theoretical positions. The formulations of Gill and Brenman (1961), White (1941), and Shor (1959) were representative of the state view. The views of Sarbin and Anderson (1967), and Barber (1969) were typical of skeptical viewpoints. Hull (1933) and Edmonston (1967) fel1 somewhere between the two polarities.

The psychoanalytic formulation of Gill and Brenman

Gi11 and Brenman (1961) regarded hypnosis as a regressive phenomenon. To explain this regression it is helpful to understand their concept of "relative autonomy." As an individual grows, the ego (represented by the functions of memory, perception, and motility) becomes relatively autonomous from environment and id impulses. The ego is not forced to respond indiscriminately to stimuli in the environment or from impulses emanating from the id. However, there are limits to the ego ${ }^{\circ} \mathrm{s}$ autonomy. It cannot, for instance, ignore the environment if the individual is trapped in a burning room. There is autonomy only when the ego is receiving information from the environment and the id, and it is not forced to respond to either.

The ego is characterized by flexibility to adjust to changing conditions as we 11 as by automatizations which are we11-established achievements that function automatical1y. Such automatized functions may be motor (tying a shoe), or cognitive (rapid, experienced solving of arithmetical problems). With automatization, intermediate steps of 
an exercise often disappear from consciousness. However, automatizations can interfere with relative autonomy if it means loss of capacity to adapt to changing conditions. Thus, de-automatization of automized functions is a part of normal functioning.

There are two ways a decrease in the ego's relative autonomy can occur: by a Iimitation or decrease in input from the environment or the id; by a strong environmental stimulus (press) or a strong id impulse (urge). If de-automatization is brought about as the result of a strong urge or press, there will result a decrease in relative autonomy. For example, loss of information from the environment coupled with a strong urge may result in the individual's coping with the enviromment solely in terms of motivation regardless of external realities: Similarly, loss of information from the id coupled with a strong press may result in motivation being restructured by the environment. If a strong press or urge is not present or does not persist when de-automatization occurs, then the consequence can be a possible increase in relative autonomy.

In hypnotic induction, the environment is changed by the behavior of the hypnotist. Manipulations of the hypnotist are attempts at disrupting the ego's control of its apparatuses. The hypnotist attempts to de-automatize the subjects automatized behaviors by consciously directing the subject's attention toward them. With attention absorbed in the task, the subject receives diminished input from the environment. The hypnotist thus deprives the subject of information from the environment and exerts a strong pressure on him 
to behave in the manner which he directs. This compliance to the hypnotist results in a decrease in autonomy from the id and the environment. The ego must search for a motivational pattern that will correspond to the environmental press. A subsystem is set up within the ego which has control over some re-automatized apparatuses (perception, memory, motility). It is only this subsystem which is under control of the hypnotist. The over-all ego maintains a non-hypnotic, reality oriented relationship with the hypnotist. Gill and Brenman conjecture that the over-all ego can always take control of the subsystem from the hypnotist.

This process is called regression in the service of the ego because only a subsystem has yielded control to the hypnotist. Hypnosis is an altered state of conciousness, the subject engaging in a regressive, interpersonal relationship with the hypnotist.

The formulations of White and Shor

White (1941) regarded hypnotic behavior as partly goal directed. The most general goal of the hypnotized subject is to behave like the subject understands the hypnotist expects him to behave. The subject strives to put the hypnotist's intentions into execution, but is not necessarily aware of these strivings.

Hypnosis is also an altered state of the individual wherein the subject can transcend the usual boundaries of volitional control. His former, integrative frames of reference are withdrawn in favor of a new frame of reference. He thus becomes capable of doing things that he 
normally cannot do.

White believed hypnosis to be a midpoint along a continuum going from relaxation to sleep. The hypnotist should keep the subject in a "light drowsiness" condition. He prevents the subject from fal1ing into sleep by continually talking to him. Thus two factors are necessary and operative in al1 hypnotic induction techniques: relaxation and a reduction in sensory input; the presence of an operator who administers the suggestions.

Shor (1959) has expanded on White's conceptions of an altered state of consciousness characterized by withdrawn frames of reference. In the usual state of consciousness, a person has a structured frame of reference which supports and gives meaning to experiences, which Shor calls the "generalized reality-orientation." This realityorientation does not maintain itself without active efforts, although one is usually not consciously aware of such efforts. Whenever its support diminishes, the generalized reality-orientation fades into the background of attention and becomes relatively nonfunctional. Times when the reality-orientation completely slips away occur during sleep, hypnosis, or in the complete absorption in a task or in a stimulus, such as music. Different aspects of the generalized reality-orientation emerge into the central background of attention depending on the special cognitive requirements of the immediate situation. For example, when watching a baseba11 game, the rules of the game may become centra1.

In normal waking life, all aspects of the generalized 
reality-orientation are in close communication at all times. In tiie hypnotic trance, close communication is lost. The trance is a state in which the generalized reality-orientation has faded into relatively "nonfunctiona1 unawareness." This can happen when an individual becomes extremely absorbed in one segment of reality, which can be brought about by the hypnotic induction procedure. Hypnosis is a state of isolation; behaviors function in isolation from the totality of generalized experiences. Suggestibility, or hypersuggestibility, is a secondary consequence of isolation.

When the generalized reality-orientation fades, experiences cannot have their usual meanings. As a result of their isolation from the totality of general experiences, they have acquired special meanings and become special orientations. The "good" hypnotic subject is thus a person who has the ability to voluntarily give up his usual reality-orientation, and who can concurrently build up a new, special orientation to reality which temporarily becomes the whole of reality for him. Depth of trance is indicated by the degree to which the generalized reality-orientation fades into nonfunctional unawareness. The depth of the subject 's role takjng (White's conception of the subject as attempting to meet the hypnotist's expectations) is determined by the extent to which the subject builds up a new, special orientation. Hypnosis is a combination of both trance and role taking behavior.

The stimulus-response view of Hull and Edmonston

Hu11 (1933) saw hypnosis as a state which differed 
quantitatively from the normal waking state. He was thus more conservative in his view than Gil1 and Brenman, and White and Shor, who saw hypnosis as qualitatively differentiated from a normal waking state. However, Hull did imply that the quantitative change is a specific result of a hypnotic induction technique, and, at least initial1y, is involuntary.

Hypnosis is essentially a habit phenomenon. Words are stimulus acts which function as stimuli to evoke other acts. Words have acquired the capacity to elicit reactions through the processes of association and conditioning. An idea represents a pure stimulus act which plays continuously on the neuromuscular equipment of the individual and may be represented by a number of words. Attention means that an individual reacts to a single stimulus idea for a length of time without substantial change. In the case of hypnosis, there is a withdrawa1 of stimulation that normally arises from the subject's own ideas. This allows the continuous stimulation (words) emanating from the ideas of the hypnotist an opportunity to control the subject's movements. Al1 reactions which are in this way susceptible to control by suggestion are ultimately capable of being controlled voluntarily by suitable conditioning to an association with stimuli arising from the subject's own symbolic activity (ideas). This latter case would represent a condition of autohypnosis.

Edmonston (1967) in general agreed with Hull in viewing hypnosis as a habit phenomenon. He cited research evidence in support of this contention. He reported that hypnosis had been shown to obey 
the following characteristics of a habit: it was facilitated by practice; this facilitation took the form of a negatively accelerated practice curve; with disuse a partial decrement of facility occurred; the decrement was recovered with less practice than was needed for origina1 learning; and transfer of training from one response or condition to another occurred.

The role enactment conception of Sarbin and Anderson Sarbin and Anderson (1967) saw hypnosis as the enactment of a role. They were skeptical that hypnosis was anything different behaviorally or beyond what a person is capable of in everyday, normal life. Role enactment is not simply playing a role. It connotes involvement, commitment, and seriousness," The hypnotic subject attempts to perform his role in accordance with the expectations and wishes of the hypnotist. The subject's subsequent behavior may or may not be genuine.

Sarbin mentioned social psychological variables that described interaction between hypnotist and the subject. Expectations that the subject brings with him, derived from varied sources (e.g., mass media), and the expectations he perceives the hypnotist as having, determine outcome. If the subject expects that he cannot be hypnotized, or resists the expectations of the hypnotist, the subject will not perform. The subject must also perceive the role expectations the hypnotist has for him accurately. Sufficient information must be transmitted. Subjects can also perform best those roles which best conform to skills or 
natural tendencies the subject brings with him. The subject can thus absorb himself most completely in those roles which are most characteristic of himself. These are roles that he is most comfortable with. It is harder to accept a role which is unusual or which is potentially embarrassing. Some subjects are more sensitive than others in perceiving the unspoken demands of how they are expected to behave hypnotically. Good hypnotic subjects are those who have a sensitivity to role demands and who can become absorbed in involving themselves in a role.

Sarbin did not use a trance concept. He asserted that the "trance" state had not been specified in objective terms. In addition, many hypnotic behaviors could be elicited without hypnotic induction procedures. This problem with the trance concept will be expanded upon below.

The "empirically-based" formulation of Barber

Barber (1964a) has been most vigorous in arguing against the necessity of employing a "trance" concept. Most investigators have agreed that the term "hypnosis" or "trance" connotes an altered state of awareness or a peculiar subjective state. However, criteria for denoting this stace have not been specified. Investigators have not agreed on behavioral characteristics of the "trance" state. Some common characteristics mentioned are literal mindedness, lack of spontaneity and initiative, loss of mobility, rigidity of facial expression, etc. However, subjects showing these characteristics may have been relatively unresponsive to suggestions (Barber, 1963a), and other 
subjects responded at a high level of suggestibility without showing these characteristics (Barber \& Calverley, 1962a; Klopp, 1961). No one has been able to demonstrate any reliable physiological indices of a hypnotic state (Barber, 1961; Crasilneck \& Ha11, 1959; Edmonston, 1968; Levitt \& Brady, 1963)。

Barber (1964a) indicated that the chief criterion for inferring a hypnotic state was a heightened level of response to suggestion. The antecedent or causal variable (hypnotic state) was inferred from the consequent or dependent variable (response to suggestions). This reasoning was circular or tautological: "a person is said to respond to suggestions because he is in hypnosis and he is said to be in hypnosis because he responds to suggestions" (p.839).

Even if investigators could agree on the behavioral indices of hypnosis, indices or characteristics may be responses to direct or indirect suggestions of relaxation.

If this is the case, the statement that hypnosis is necessary or sufficient to produce positive response to suggestions tends to be somewhat trivial since it says no more than that positive response to some suggestions ( $\mathrm{e}_{\circ} \mathrm{g}_{\circ}$, suggestions of relaxation, drowsiness, or passivity) is necessary or suf: ficient to evoke positive response to other suggestions (Barber, 1964a), p. 840).

Barber (1969a) evolved a paradigm that did not postulate a special state of consciousness. Hypnotic-like behaviors observed were attributed to antecedent variables that were generally found in interpersonal relationships. The main focus of research was to determine the operative antecedent variables, their inter-relationships and their effect on consequent variables. 
Barber specified three general types of consequent variables: responses to test-suggestions to perform in a certain manner; subject's reports of having been hypnotized; and hypnotic appearance (1iteral mindedness, psychomotor retardation, etc.). Important antecedent variables included instruction-suggestion variables which defined the situation and produced positive or negative task motivation; subject variables such as attitudes and expectations; experimenter or hypnotist variables such as prestige, expectancies, biases; and subject-experimenter variables such as the nature of their interpersonal relationship. The final phase of research was to specify the functional relations existing between antecedent and consequent variables.

Variables Related to Hypnotic Behavior

Until relatively recently, the great majority of studies done in the field of hypnosis have not employed control groups. Therefore, much of hypnotic behavior was attributed to the effects of a trance induction procedure. In such a procedure, the hypnotist generally tells the subject (S) to progressively relax, to concentrate on his words to the exclusion of any other thoughts or concerns, and to respond positively to his suggestions. However, a number of studies employing control groups found that direct suggestions or instructions to imagine the suggestions of the experimenter (E) produced the same behavioral effect as when those suggestions were given under trance following a hypnotic induction procedure. Some examples of successful duplication of hypnotic S 
to suggestions to hallucinate (Barber \& Calverley, 1964a; Bowers, 1967; Thorne, 1967), to be analgesic to a painful stimulus (Barber \& Hahn, 1962; Shor, 1962), to be deaf (Barber \& Calverley, 1964b) to distort time (Barber \& Calverley, 1964c) and to be color blind (Barber \& Deeley, 1961). The impact of studies such as these has been to stimulate research into the factors related to hypnotic behavior.

\section{Subject expectations}

Orne $(1959,1962)$ demonstrated that the demand characteristics of any particular experiment played an important role in $\underline{S}$ performance. Demand characteristics referred to implicit or explicit demands made on $\underline{S}$ to respond in specified ways in the experimental setting. Implicit demand characteristics could be inferred by $\underline{S}$ from $\underline{E}$ 's behavior, the experimental setting, comments of other $\underline{S} s$, etc. Naturally, implicit demands could influence $\underline{S}$ 's expectations of how he was supposed to behave. Orne (1959) exposed a number of people to a fabricated hypnosis demonstration wherein the $\underline{S}$ feigned a hypnotic trance. The audience thought the demonstration was real. While in the feigned trance, the $\underline{S}$ s exhibited hand catelepsy (rigidity). Orne later hypnotized some of the individuals who had witnessed the fabricated demonstration. Al1 these $\underline{S} s$ spontaneously exhibited hand catelepsy without $\underline{E}^{\prime}$ 's suggestion, although hypnotic $\underline{S} s$ normally do. not show catelepsy unless it is specifically suggested. Orne concluded that $\underline{\text { 's }}$ prior knowledge and expectations concerning hypnotic

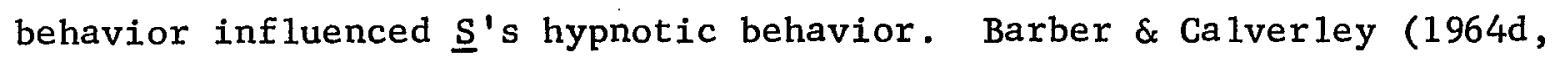
1965a) assigned Ss randomly to one of two groups. In one group, Ss 
were told that they were participating in a hypnotic experiment; in the other group, Ss were told that they were being tested for their ability to imagine. Ss in both groups were then treated identically, none of them being hypnotized. They responded to items from the Barber Suggestibility Scale (BSS). Heightened responsiveness to such a scale reflected compliance to E's suggestions. $\underline{S}$ s in the group that were told that they were participating in a hypnotic experiment were significantly more responsive to BSS items. Zamansky, Scharf \& Brightbil1 (1964) found Ss were more responsive to suggestions in sessions where they were led to believe that they would be hypnotized. Ss apparently "decided" that they would be more suggestible if the experimental situation was defined as hypnosis. Other studies showed

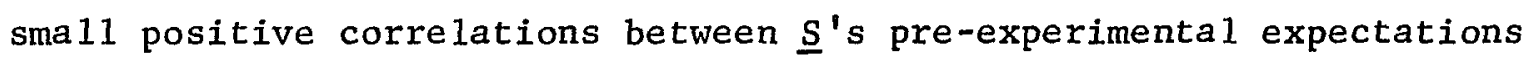
of his ability to achieve hypnotic depth and his responsiveness to test suggestions (Barber \& Calverley, 1966a; Derman \& London, 1965; Melei \& Hilgard, 1964; Shor, Orne, \& O'Conne11, 1966).

Instructions or other communications $\underline{S}$ receives from $\underline{E}$ may influence his expectations and alter his hypnotic performance.

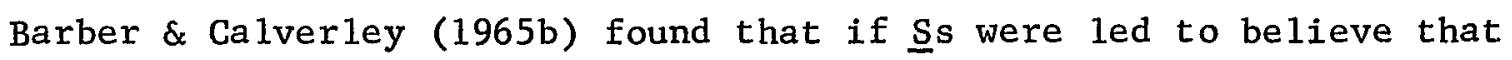
the procedure used in inducing hypnosis was usually not effective, they

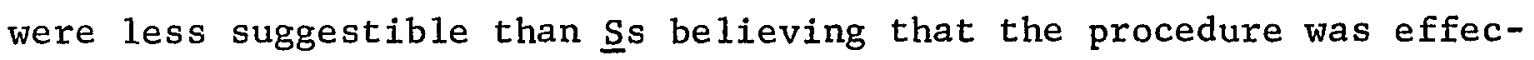
tive. Similarly, Ss were more responsive to test suggestions on the BSS when they were told that the tests were easy rather than difficult to perform (Barber \& Calverley, 1964d).

$\underline{S}$ appears to generally have an implicit trust in $\underline{E}^{\prime} s$ 
intentions. Young (1952) demonstrated that deeply hypnotized $\underline{S}$ would carry out apparent dangerous and anti-social activities. However, Orne and Evans (1965) demonstrated that any $\underline{S}$ treated in a sufficiently similar manner to the deeply hypnotized $\underline{S}$ would also carry out dangerous or anti-social activities. Ss had an apparent expectation that E's experimental procedures were safe and that $\underline{E}$ would not

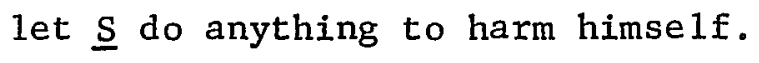

\section{Experimenter expectations}

The expectations of $\underline{E}$ can have important effects on $\underline{S}$ 's behavior. Wolberg (1948) reported a dramatic example of an $\underline{s}$ 's attempt to satisfy $\underline{E}^{\prime}$ s expectations. E gave $\underline{S}$ the posthypnotic suggestion that $\underline{S}$ would develop hives on his forearm. In order to comply with this suggestion, $\underline{\mathrm{S}}$ had picked poison ivy and rubbed it on his forearm on his way home from the hypnotic session. S later vigorously denied that he had intentionally irritated his arm until he was put into a trance. Fisher (1954) gave $\underline{S}$ s a posthypnotic suggestion that they would scratch their ear every time they heard a particular stimulus word. When $\underline{E}$ gave $\underline{S}$ s the impression that the experiment was completed, almost a11 of them stopped responding to the stimulus word. Posthypnotic behavior apparent ly continued as a function of the belief that $\underline{E}$ expected the behavior to occur.

Ss testimony of subjective reports have also been demonstrated to conform to what $\underline{S}$ infers as E's expectations. S s told by E that they appeared very deeply hypnotized responded with 
self-ratings as more deeply in a trance than other $\underline{\text { s }}$ who were just as responsive to the same test suggestions (Barber, Dala1, \& Calverley, 1968). These Ss also responded with a "yes" answer when asked, "Did you feel you could resist the suggestions?" Eighty-three percent of

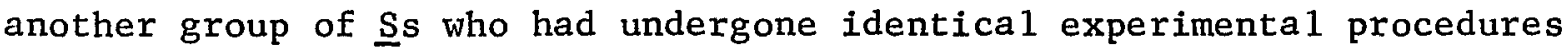
also responded with "yes" when asked, "Did you feel you could not resist the suggestions?"

Experimenter bias has been shown to have influenced the results of many psychological experiments (Barber \& Silver, 1968; Rosentha1, 1968). It is a particularly important factor in hypnosis experiments because the hypnotic $\underline{S}$ appears to be highly motivated to conform to expectations he infers E as having.

Troffer and Tart (1964) did a study which indicated how difficult it is for $\mathrm{E}$ to mask his expectancies. Eight $\underline{E}$ were used as hypnotists. Each $\underline{S}$ was given parallel forms of the Stanford Hypnotic Susceptibility Scale (SHSS) on two successive days by a different $\underline{E}$ on each day. Items on this scale consisted of suggestions to which $\underline{S}$ responded. On the first day, $\underline{S}$ was told to imagine the sHSS items; on the second day, $\underline{\text { s w }}$ hypnotized and then given the SHSS items. Each E administered both the imagining and hypnosis conditions. E knew that he was being tested for $\underline{E}$ bias, and was urged to be as consistent as possible in both conditions. Tape recordings were made of E's administration of the SHSS under both conditions. Judges later were able to decide at a highly statistically significant level which condition $\underline{E}$ was in solely from listening to his tape recorded voice. 
Judges described E's typica1 voice in the hypnosis condition as being more relaxed, soothing, coaxing, and descriptive as opposed to a more casual, businesslike, and alert sounding voice in the imagination condition. Thus these sophisticated Es failed to mask their bias, although they were aware of the purpose of the study!

Task motivation

The motivation $\underline{S}$ has to perform the experimental task influences his responsiveness to suggestions in hypnosis experiments. In one study, $\underline{S}$ were assessed on the BSS after receiving positive, neutral and negative attitudinal-motivational pretest instructions. A11 Ss were told that they were being given a test of imagination, none of the $\underline{S}$ s receiving hypnotic induction procedures. $\underline{S} s^{\prime}$ responsiveness to BSS items was positively related to how motivating the pretest instructions were (Barber \& Calverley, 1964e). In another study, Barber and Calverley (1968) assessed responses to suggestions under the following treatments: motivational instructions (MI) alone; hypnotic induction (HI) and MI together; imagination-control (IC). Comparisons were made across independent groups and within $\underline{S} s$ over conditions. The MI and HI + MI conditions raised suggestibility

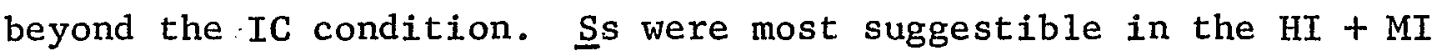
condition which the investigators interpreted as reflecting the greater effectiveness of the hypnotic procedure in defining the situation as one in which heightened suggestibility occurs. A number of other studies also demonstrated that positive task motivation 
increases suggestibility (Barber \& Calverley, 1962, 1963a, 1963b, 1965b; Edmonston \& Robertson, 1967; Slotnick, Liebert, \& Hilgard, 1965; Slotnick \& London, 1965).

Hartman (1967) reported a study which showed an increase in $\underline{S}$ responsiveness to BSS items as a function of $\underline{E}^{\prime} \mathrm{s}$ attitude (friendly, neutral, or hostile) rather than due to high or low task motivation conditions (high task motivated S s were encouraged and assured they could perform the tasks). However, E's attitude may have been enough to alter motivation by determining if $\underline{S}$ did or did not want to satisfy E's expectations.

Role playing aptitude

There is some evidence, which supports Sarbin and Anderson's (1967) view, that role playing ability is positively related with hypnotic-like performance. Coe and Sarbin (1966) found that $\underline{S}$ sho were drama students were better hypnotic $\underline{S}$ s than a group of science students. The former were presumed to be higher in role taking aptitude. However, London and Madsen (1968) did not find "dramatic acting" ability related to hypnotic susceptibility in children.

\section{Status of the Trance Concept}

Does a trance induction procedure result in behavior qualitatively or quantitatively different than what can be manifested without such a procedure? Barber (1969a) and Sarbin and Anderson (1967) would answer this question negatively. The great majority of investigators in this field would disagree with them. A number of controlled 
studies have been performed to answer the question.

Problem of controls

Orne (1959) was one of the first investigators in this field to point out the necessity of having a control group which is treated in the same manner as the experimental group. He proposed a simulator control method. In this method, a group of $\underline{S} s$ who were insusceptible or unresponsive to hypnotic suggestions were instructed to simulate hypnotic performance. They were then exposed to exactly the same treatment as an experimental group of susceptible hypnotic Ss. Simulators were subjected to a trance induction procedure by an $\underline{E}$ other than the one who instructed them. The $\underline{E}$ administering the trance

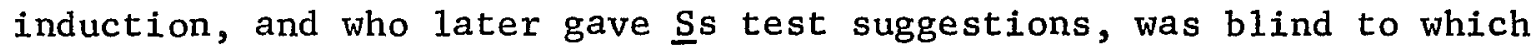
group (simulator or susceptible) any particular $\underline{S}$ belonged. The simulators, being insusceptible, were not hypnotized by the induction procedure. However, task motivation was kept at a high level for the simulators by informing them that if the hypnotist $\mathrm{E}$ discovered they were faking, they would be excluded from the experiment. It was found that simulators could successfully fool a hypnotist $\underline{E}$ under these circumstances. Orne then reasoned that any difference between the simulator and hypnotic $\underline{S} s$ were due to a trance state. Several studies reported differences in behavior between simulators and real trance subjects using Orne's method (Bowers, 1966; Orne \& Evans, 1966; Orne, Sheehan \& Evans, 1968; Over1y \& Levitt, 1968). Barber (1962a) and Chaves (1968) criticized the simulator 
control method. Hypnotic and simulating treatments were confounded with pre-existing differences in suggestibility or motivation to perform. Differences in responsiveness between the two groups may have been due to already existing differences in suggestibility or motivation rather than to effects of "hypnosis." Anderson and Sarbin (1964) commented on the necessity of taking into account the base rate of responsiveness for a population after discovering that $\underline{S}$ s who volunteered for hypnotic experiments were more responsive than those who did not volunteer. Barber and Chaves also pointed out that the experimental group usually participated in preliminary or training sessions, whereas the simulating control group did not. Thus the experimental group received more practice in complying with suggestions. A third argument was that originally simulators received different instructions on how to behave. They were told to "fake" with the implication not to experience what was suggested, whereas the experimental group was instructed to "experience" the suggestions. Such differing instructions or suggestions may have led to differences in subjective experiences.

Barber (1962a) recommended the use of an independent groups design with $\underline{S}$ s randomly assigned to each of the groups. Sss should be either selected or unselected on the basis of suggestibility. Hilgard and Tart (1966) argued that a more sensitive design is one in which $\underline{\mathrm{S}}$ is used as his own control. Such a design is appropriate as long as the order in which conditions are presented are counterbalanced. Barber has been criticized for "hypnotizing" his controls. 


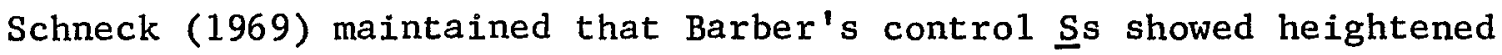
test responsiveness because the "suggestions themselves are hypnotic in nature." If such was the case, then Schneck must have agreed with Barber that hypnotic induction procedures were unnecessary and that the trance concept was superfluous in accounting for heightened suggestibility. Barber has also been criticized for the "imagination" instructions he often gave to his control groups. Hilgard (1964) asserted that such instructions were really a type of hypnotic induction; thus Barber's results with control $\underline{S} s$ could be attributed to hypnosis. However, Barber (1969b) achieved similar nonsignificant differences between controls and "hypnotized" $\underline{S}$ s administering a variety of controls. Also, imagination instructions did not conform to a standard hypnotic induction procedure. Tart and Hilgard (1966)

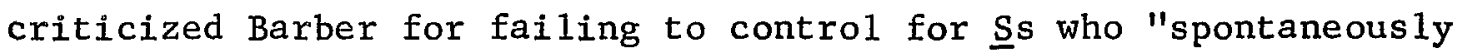
slip into hypnosis." They tested a group of $\underline{S}$, normally high in responsiveness to test suggestions in the normal waking condition, with the instructions not to allow themselves to fall into a state of

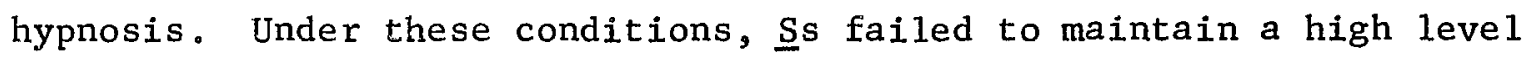
of suggestibility. Hilgard and Tart concluded that $\underline{S}$ s had to fall into a "borderline hypnotic state" if they were to be highly suggestible in a waking state. However, instructions given to $\underline{S}$ in this study were such as to strongly imply to $\underline{S}$ s that they should be less suggestible. Chaves (1968) also remarked that if it is so easy for $\underline{\text { S }}$ to fal1 into a "state of hypnosis," then everyone running any type of experiment in psychology using human Ss must constantly check to 
determine if their $\underline{S} s$ have fallen into such a state!

Studies assessing effectiveness of the hypnotic induction procedure Hypnotic induction procedures appear to be capable of allowing Ss to perform only those behaviors that they could normally voluntarily elicit or experience, albeit, it may be easier for some behaviors to be elicited under hypnosis. There is no evidence that hypnotized Ss acquire any special, supra-normal abilities. Behavior of hypnotic Ss given the suggestion that they were blind was affected by visual stimuli in contrast to those who were really blind (Barber, 1964b; Deckert \& West, 1963; Sutcliffe, 1960). Other examples of similar role playing by hypnotic $\underline{S}$ s was found for suggested deafness (Barber \& Calverley, 1964b; Kramer \& Tucker, 1967; Sutcliffe, 1961), suggested pain (Dudley, Holmes, Martin \& Ripley, 1966), suggested analgesia (Barber \& Hahn, 1962; Shor, 1962), electrodermal responses (Edmonston, 1968), and "conditioned responses" under hypnosis (Fisher, 1955). There is no properly controlled study indicating hypnotic $\underline{S} s$ acquire supra-normal abilities.

Although most investigators agreed with Barber that hypnotic Ss did not acquire supra-normal abilities, they did not agree that the hypnotic state could be entirely accounted for in terms of demand characteristics. They criticized Barber for assuming that there was no trance state just because methods other than induction could produce hypnotic-like phenomena. This did not mean that the effects were mediated by the same mechanisms as when an induction procedure was used (Bowers, 1966; Evans, 1968; Hilgard, 1965). 
Hilgard and Tart (1966), in a well designed study, found that hypnotic induction or trance conditions led to increased suggestibility over waking and imagination conditions. They used six groups of $\underline{S}$, each $\underline{S}$ tested for responsiveness in two different sessions after one of the following instructional conditions in each session: imagination with expectation of hypnosis (IE); imagination without expectation of hypnosis (INE); and hypnotic induction (HYP). A11 pairwise combinations of conditions were used. In addition three control groups received the same procedure over both sessions. Al1 instructions, induction procedures, and test suggestions were tape recorded to eliminate $\underline{E}$ bias. $\underline{S} s$ in HYP condition were significantly more responsive than when in IE or INE conditions regardless of the order in which they received the HYP condition. There were no significant differences over two sessions when control Ss were subjected to the same procedures. Tart and Hilgard concluded that there was a trance effect beyond that contributed to by demand characteristic variables. Edmonston \& Robertson (1967) obtained similar results using a similar design by comparing task motivating instructions with hypnotic induction. As previously reported, Barber and Calverley (1968) a1so found that hypnotic induction led to increased responsiveness over task motivating conditions.

The problem still remains that it is difficult to partial out the effects of demand characteristic variables. Ss in all three studies may have been more responsive in the hypnotic condition because of expectations associated with hypnotism which has been shown to be an 
important variable (Barber \& Calverley, 1964d, 1965a).

Barber and Calverley (1969) compared $\underline{S} s$ who had never participated in a hypnotic experiment before with a group of $\underline{S}$ sho were exposed to a hypnotic induction procedure. The former $\underline{S} s$ were asked to close their eyes for 5 minutes and place themselves in hypnosis. The two groups of $\underline{S}$ sere almost the same on four dimensions of hypnotic depth: trancelike appearance (limpness, relaxation, etc.); reports of unusual experiences (e.g., reported "disappearance" of body or body parts); and testimony of having been hypnotized. An additional control group who were told to close their eyes for 5 minutes were generally less responsive on all four dimensions. The "place yourse1f in hypnosis" group differed to a smal1 degree from the hypnotic induction group on some characteristics of trance-like appearance such as "trance stare" and psychomotor retardation. This result may have been the consequence of direct suggestions to relax in the hypnotic induction procedure. Ss in the hypnotic induction group were also more responsive to some test suggestions than the other experimental group. Similarities on the four dimensions of hypnotic depth displayed by the two experimental groups in contrast to the control group indicated the effect defining the experimental task as being hypnotic had on test suggestion responsiveness. The above reported findings showing greater responsiveness following hypnotic induction of Barber and Calverley (1968), Edmonston and Robertson (1967), and Hilgard and Tart (1966) were not surprising in light of this study. 
The hypnotic induction procedure and posthypnotic behavior

Posthypnotic behavior refers to acts carried out by $\underline{\mathrm{s}}$ in response to suggestions given $\underline{S}$ while in trance following a hypnotic induction. The posthypnotic acts are carried out some time after $\underline{\mathrm{S}}$ is awakened from the trance state. Many investigators maintained that posthypnotic behavior is characterized by a compulsion which is hard for $\underline{S}$ to resist and results from an altered or dissociated state of awareness (e.g., Erickson \& Erickson, 1941; Estabrooks, 1943; Hi1gard, 1966; Le Cron \& Bordeaux, 1949; Sheehan \& Orne, 1968). Another explanation was that posthypnotic behavior is simply the result of suggestion (Barber, 1962b).

Most studies supported the thesis that posthypnotic acts are the result of implicit or explicit suggestion (Barber, 1962; Orne, 1966). For instance, Sss given the posthypnotic suggestion that they would be amnesic for material learned during a trance would later show practice effects for the "forgotten" material, and would report the material if given permission to do so (Barber, 1962b; Barber \& Calverley, 1966b; Graham \& Patton, 1968). Ss never hypnotized would carry out posthypnotic acts as well as $\underline{\text { S }}$ given the same posthypnotic suggestions while hypnotized (Barber \& Calverley, 1962; Barber \& Glass, 1962).

Several investigators reported on the phenomenon of spontaneous amnesia for events which occurred in a trance state (e.g., Furneaux, 1946; Hilgard, 1966). Ss were supposed1y amnesic for trance events although never given suggestions to be so. If such were the 
case, then spontaneous amnesia for trance events could reasonably be attributed to the occurrence of such events in a trance state that was dissociated from the normal, waking state. Reported spontaneous amnesia was less frequent than suggested amnesia (Cooper, 1966; Hilgard, 1966; Hilgard \& Cooper, 1965). Barber (1962b) questioned the validity of spontaneous posthypnotic amnesia. Expectations by Ss that they should be amnesic may have led them to report amnesia spontaneously. Studies by Dorcus, Brintna11, and Case (1941), and London (1961) lent support to Barber's interpretation. In these studies questionnaires were administered to college students concerning beliefs about hypnotism and respectively found that $64 \%$ and $74 \%$ of $\underline{S}$ believed that they would be amnesic for events occurring in a trance.

Some studies attempted to show that simulating $\underline{\text { s }}$ behaved differently than real hypnotic $\underline{S}$ s in response to posthypnotic suggestions. Edward (1965) gave $\underline{S}$ s the posthypnotic suggestion that they would slow down their time to pressing a key as fast as possible. Simulating control $\underline{\text { S }}$ were asked to behave as if hypnotized. In the first experimental period, E sought to motivate $\underline{S}$ in both groups not to comply with the posthypnotic suggestion by telling each $\underline{\mathrm{S}}$ that he would receive an electric shock if his reaction time was slowed. Edward found that both the hypnotic and simulator groups speeded up, but the simulator group significantly more than the hypnotic group. Orne, Sheehan, and Evans (1968) found that 5 of 17 hypnotic S ss continued to comply with a posthypnotic suggestion outside of the experimental setting (in secretary's reception office), whereas such 
compliance was not observed for simulating $\underline{S}$. Bowers (1966) found

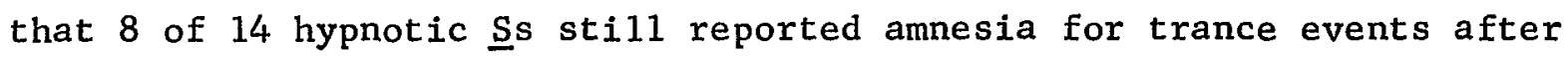
being led to believe the experiment was over, whereas none of 13 simulating Ss reported that they were amnesic. Williamsen, Johnson and Erikson (1965) found that simulating $\underline{S}$ s overplayed their roles. Hypnotic $\underline{S}$ s were given the posthypnotic suggestion that they would not remember any words they learned during a trance state when later given a word recognition task. Hypnotic Ss recognized some of the words, although simulators claimed that they did not recognize any. Since all of these studies used simulator controls, they are open to the criticisms made above with regard to the use of this type of control group (Barber, 1962a; Chaves, 1968).

Barber and Calverley (1966b) used two types of simulators in a study measuring the effectiveness of posthypnotic amnesia. They found the waking simulators did not differ from hypnotic simulators (Ss who were instructed to simulate and then given a posthypnotic suggestion for amnesia following trance induction) on reports of posthypnotic amnesia. Additional groups of waking $\underline{S}$ s and hypnotic $\underline{S} s$ also did not differ from each other when given identical suggestions for posthypnotic amnesia. When the experiment was over most all groups verbalized that they remembered a11 or most of the "forgotten" materia1. Type of suggestions and instructions administered thus appeared to be important in determining the nature of posthypnotic behavior displayed. The previous studies mentioned using simulating and hypnotic SSs delivered different instructions and suggestions to each group. 


\section{Significance of the Present Study}

The present study tested the hypothesis that occurrence of presumably compulsive and irresistable posthypnotic behavior can be entirely accounted for by direct suggestion and operating demand characteristics, induction of a trance state being unnecessary and adding no quantitative changes in the occurrence of the behavior.

As mentioned earlier, Fisher (1954) found that Ss stopped exhibiting a posthypnotic act when led to believe the experiment was concluded. However, Fisher's conclusion that $\underline{S}$ s were simply attempting to satisfy the expectations of $\underline{E}$ has been criticized by Sheehan and Orne (1968). They claimed that $\underline{S}$ s in the Fisher study may have understood that the posthypnotic suggestion implied that the posthypnotic act was to be operative only as long as the experiment lasted. Therefore, it should not be surprising that the behavior stopped at what appeared to be the conclusion of the experiment. Previously reported studies (Bowers, 1966; Edward, 1965; Orne, et a1., 1968) showing hypnotic Ss as being more compliant to posthypnotic suggestions than simulating $\underline{S}$, although confounded with pre-existing differences between the two groups as well as differing instructions to each group, leave the purported compulsive and irresistable qualities of compliance to posthypnotic suggestion open to question.

The present study sought to determine what would happen if some Ss were instructed to resist a posthypnotic suggestion when given the suggestion either before or after trance induction. $\underline{S}$ 
were also given positive or negative expectations as to their ability to resist the suggestion. As a control, al1 Ss were hypnotized so that the situation was uniformly defined as one involving hypnosis.

It was hypothesized that $\underline{S} s^{\prime}$ response to the suggestion would be determined by what expectations they had regarding their ability or inability to resist the suggestion. It was further hypothesized

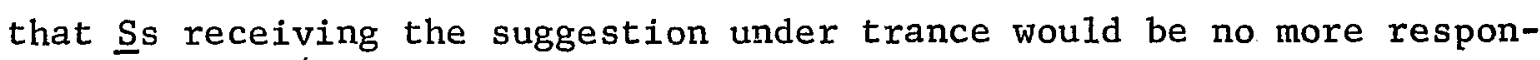

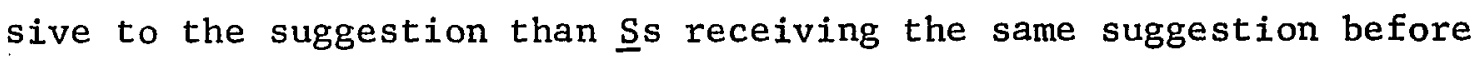
trance given that both groups of $\underline{S}$ s harbored similar expectations. 
METHOD

Selection of subjects: Fifty-four volunteer undergraduate female students enrolled at Louisiana State University were included in the study. Females were used because past studies had shown them to be generally more susceptible to hypnotic induction, and more reliable in attending the many meetings necessary in this type of experiment (Dawson, personal communication, 1970). Ss were given the Minnesota Multiphasic Personality Inventory and an interview (appendix A) in order to eliminate $\underline{S}$ s who may have had severe personality or medical problems. One $\underline{\mathrm{S}}$ was excluded from the experiment for reasons of emotional disturbance. She received psychological counseling. Ss were then given items from the Stanford Hypnotic Susceptibility Scale (SHSS), forms A and B (appendix A) in two training sessions. Only $\underline{S}$ s who responded positively to at least 10 of these test suggestions were used in the study. Ss were required to respond positively to the posthypnotic suggestion (item 11).

Ss were also administered the Digit Symbol test from the Wechsler Adult Intelligence Scale (Wechsler, 1955). The test was administered in standardized fashion to obtain a base score with which to compare later performance on the same test.

Experimenta1 procedure: A tape recorder was used to administer a standard hypnotic induction (Hilgard, 1965), and the posthypnotic suggestion, to all Ss during the experiment proper. 
Standardized tape recorded presentations have the advantage of reducing or eliminating E bias. Studies by Barber and Calverley (1964f), Hoskovec, Svorad, and Lanc (1963), and Thorne and Beier (1968) have shown that very similar performances are elicited from $\underline{S} s$ regardless of whether suggestions are presented by $\underline{E}$ or a tape recorder.

A11 Ss participated in the following four phases of the study in this order: prehypnotic induction instructions administered by $\underline{E}_{1}$; hypnotic induction administered by tape recorder in the presence of $\underline{E}_{2}$; performance on a posthypnotic task in presence of $\underline{E}_{2}$; and a post-experimental inquiry conducted by $\underline{E}_{2}$.

There were two main factors or treatment variables: an "instructional-expectational" factor, and a "posthypnotic suggestion" factor. Each $\underline{S}$ fell into 1 of 3 conditions under the instructiona1expectational factor and also into 1 of 3 conditions under the posthypnotic suggestion factor. An equal number of $\underline{S} s$ were assigned to al1 9 possible combinations of conditions between the 2 factors. There were $6 \underline{s}$ s per treatment combination.

\section{Instructional-expectationa 1 factor conditions}

Instructions and expectations were administered by $E_{1}$ in the absence of $\underline{E}_{2}$ while $\underline{S}$ was awaiting hypnotic induction. There were 3 conditions under this factor:

(1) Resistance with positive expectation (RE+):

$\underline{S}$ was told by $\underline{E}_{1}$ to resist performing the posthypnotic suggestion that $\underline{S}$ was to receive while in trance. $\underline{E}_{1}$ 
imparted to $\underline{S}$ the expectation that $\underline{S}$ would successful1y resist performance of the act (appendix B).

(2) Resistance with negative expectation (RE-):

$\underline{\mathrm{S}}$ was given the same instructions as in $\mathrm{RE}+$, except that $\underline{E}_{1}$ imparted to $\underline{S}$ the expectation that $\underline{S}$ would not be able to successfully resist performance of the act (appendix B).

(3) Neutra1 (N):

$\underline{S}$ was not given any instructions to resist the posthypnotic suggestion or any expectation regarding her posthypnotic behavior. $\underline{S}$ was only told by $\underline{E}_{1}$ that she was to be hypnotized shortly by $\underline{E}_{2}$.

\section{Posthypnotic suggestion factor conditions}

This factor refers to the differing conditions under which the posthypnotic suggestion was administered. The posthypnotic sug-

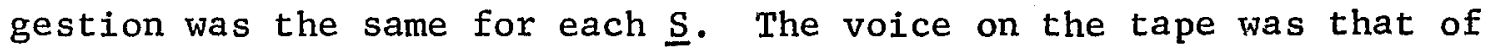
$\underline{E}_{2}$. The posthypnotic suggestion essentially was that $\underline{\mathrm{S}}$ would not be able to perform as well as the first time on the Digit Symbol test when it was administered to $\underline{S}$ posthypnotically (appendix C). The three conditions under this factor were:

(1) Posthypnotic suggestion administered before trance induction (PHS): $\underline{S}$ heard the posthypnotic suggestion in the presence of $\underline{E}_{2}$ immediately before trance induction. $\underline{S}$ was told that hearing a suggestion directly before trance induction has 
the same effect as when a suggestion is administered during trance. $\underline{S}$ was also told that she would not receive the suggestion while in trance. $\underline{E}_{2}$ then hypnotized $\underline{\mathrm{S}}$, after which $\underline{\mathrm{S}}$ was awakened. No posthypnotic suggestion was administered during trance. (2) Posthypnotic suggestion administered after trance induction with reported amnesia (PHS-TA):

S was administered the posthypnotic suggestion immediately after she was hypnotized. $\underline{S}$ was then told that she would not remember the events occurring during the trance after she was awakened. Only those $\underline{S}$ seporting amnesia or vague partial memory of trance events were retained in this condition.

(3) Posthypnotic suggestion administered after trance induction with no reported amnesia (PHS-T):

Ss in this condition underwent the same procedures as did PHS-TA Ss. They differed only in that they clearly remembered what occurred during trance.

Ss were hypnotized in groups of 5 to 8 . A11 Ss within a group belonged to the same posthypnotic suggestion condition, but varied with respect to which instructional-expectational condition they were assigned. $\underline{E}_{2}$ was always blind as to which instructional-expectationa 1 condition each $\underline{S}$ belonged.

A11 $\underline{\text { S }}$ received the same treatment on the experimental task. After being awakened from the hypnotic trance, each $\underline{S}$ was administered 
the same Digit Symbol test that they had taken earlier.

Upon completion of the Digit Symbol test, $\underline{E}_{2}$ told $\underline{S}$ that the experiment was over. $\underline{E}_{2}$ asked $\underline{\mathrm{S}}$ what she was told by $\underline{E}_{1}$. If $\underline{\mathrm{S}}$ was in either the RE+ or RE- condition, she was told that $E_{1}$ and $\underline{E}_{2}$ really did not have any particular hypothesis concerning s's ability to resist the posthypnotic suggestion. $\underline{S}$ was then urged to be honest in answering the following questions:

Do you remember what happened during the trance state? What were your thoughts and experiences while taking the Digit Symbol test?

At any time did you disbelieve what was told to you by either of the experimenters?

Did you ever think of any reasons behind the experiment other than the ones stated to you? Following the post-experimental inquiry, al1 ss were rehypnotized to remove any effects of the posthypnotic suggestion. 
RESULTS

Posthypnotic suggestion (P-S) conditions and the instructiona1expectational (I-E) conditions are represented by a $3 \times 3$ analysis of variance design as shown in Table 1 . Mean performance of $\underline{s}$ in each treatment combination reflected change in performance over two administrations of the Digit Symbol test. ㅇ's score from the first administration of the test was subtracted from $\underline{S}^{\prime} s$ score on the second administration, and the result added to a constant of 100 to yield a posthypnotic score. Thus any posthypnotic score above or below 100 respectively indicated improved or deteriorated performance on the second administration of the test.

A summary of the analysis of variance appears in Table 2 . There were significant differences $(\mathrm{P}<.01)$ over both $\mathrm{P}-\mathrm{S}$ and $\mathrm{I}-\mathrm{E}$ factors. The Newman-Keuls test of mean comparisons (Winer, 1962) further indicated that all three P-S conditions differed significantly from each other $(p<.01)$. Comparisons over I-E conditions showed significant differences $(p<.01)$ between $R E+$ and either of the $N$ or RE- conditions, although RE- and $\mathrm{N}$ did not differ from each other. Tables 3 and 4 show significance of differences between any two conditions under one factor for any one condition on the other factor. Figures 1 and 2 graphically illustrate the comparisons made in Tables 3 and 4. Differences between RE+ S-s in PHS and PHS-TA conditions were almost significant as were the differences between RE+ and either the RE- or $\mathrm{N}$ Ss in the PHS-T condition. 
TABLE 1

ANALYSIS OF VARIANCE DESIGN WITH CELL MEANS

AND OVERALL MEANS OF POSTHYPNOTIC SCORES

\begin{tabular}{l|r|c|c|r}
\hline \multirow{2}{*}{$\begin{array}{c}\text { P-S } \\
\text { Conditions }\end{array}$} & \multicolumn{4}{|c|}{ I-E Conditions } \\
\cline { 2 - 5 } & $\mathrm{N}$ & $\mathrm{RE}-$ & \multicolumn{2}{c}{$\mathrm{RE}+$} \\
\hline PHS & 74 & 76 & 104 & 85 \\
PHS-T & 88 & 90 & 101 & 93 \\
PHS-TA & 61 & 59 & 92 & 71 \\
\hline & 74 & 74 & 99 &
\end{tabular}


TABLE 2

ANALYSIS OF VARIANCE

\begin{tabular}{ccccc}
\hline Source & df & MS & F & p \\
\hline P-S Conditions (A) & 2 & 2306.92 & 18.99 & $<.01$ \\
I-E Conditions (B) & 2 & 3556.42 & 29.29 & $<.01$ \\
A X B & 4 & 230.26 & 1.89 & \\
Error & 45 & 121.42 & & \\
Tota1 & 53 & & & \\
\hline
\end{tabular}


TABLE 3

SIGNIFICANCE OF DIFFERENCES BETWEEN ANY TWO

P-S CONDITIONS FOR EACH I-E CONDITION

\begin{tabular}{|c|c|c|c|}
\hline \multirow{2}{*}{$\begin{array}{l}\text { P-S Conditions } \\
\text { Compared }\end{array}$} & \multicolumn{3}{|c|}{ I-E Conditions } \\
\hline & $\mathrm{N}$ & $\mathrm{RE}-$ & $\mathrm{RE}+$ \\
\hline PHS__PHS-T & $*$ & $*$ & ns \\
\hline PHS_PHS-TA & * & $*$ & ns \\
\hline PHS - T____ PHS -TA & $* *$ & $* *$ & ns \\
\hline
\end{tabular}

ns nonsignificant difference

$* \mathrm{p}<.05$

$* * \mathrm{p}<.01$ 
TABLE 4

SIGNIFICANCE OF DIFFERENCES BETWEEN ANY TWO

I-E CONDITIONS FOR EACH P-S CONDITION

\begin{tabular}{c|ccc}
\hline $\begin{array}{c}\text { I-E Conditions } \\
\text { Compared }\end{array}$ & \multicolumn{3}{|c}{ P-S Conditions } \\
\cline { 2 - 4 } & PHS & PHS-T & PHS-TA \\
\hline $\mathrm{N}-\mathrm{RE}-$ & $\mathrm{ns}$ & $\mathrm{ns}$ & $\mathrm{ns}$ \\
$\mathrm{RE}-\mathrm{RE}+$ & $* *$ & $\mathrm{~ns}$ & $* *$ \\
$\mathrm{~N}$ & $* * *$ & $\mathrm{~ns}$ & $* *$ \\
\hline
\end{tabular}

ns nonsignificant difference

$* * \mathrm{p}<.01$ 
FIGURE 1

P-S S S' MEAN POSTHYPNOTIC SCORES ON THE

DIGIT SYMBOL TEST OVER I-E CONDITIONS
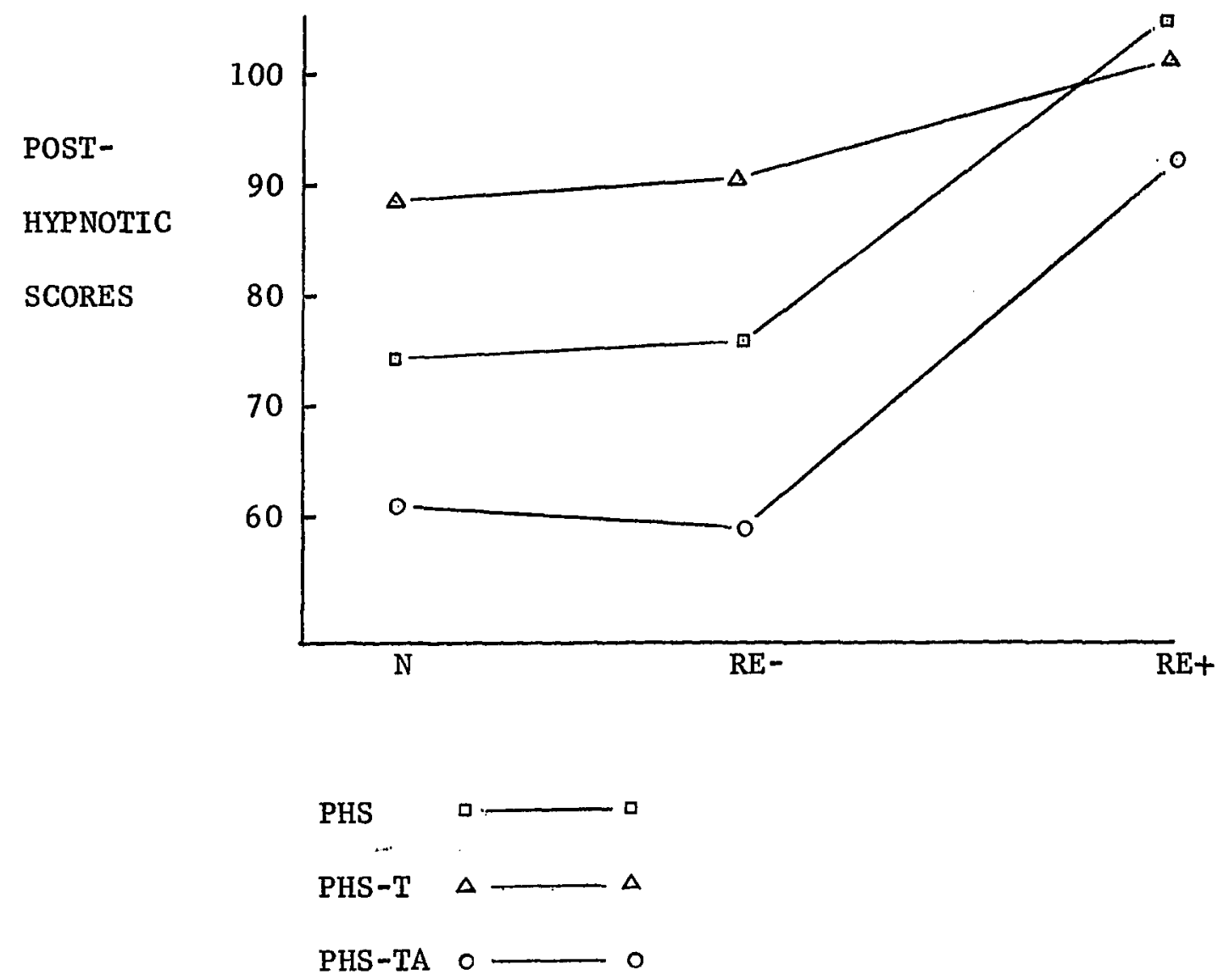
FIGURE 2

I-E S $s^{\prime}$ MEAN POSTHYPNOTIC SCORES ON THE DIGIT SYMBOL TEST OVER P-S CONDITIONS

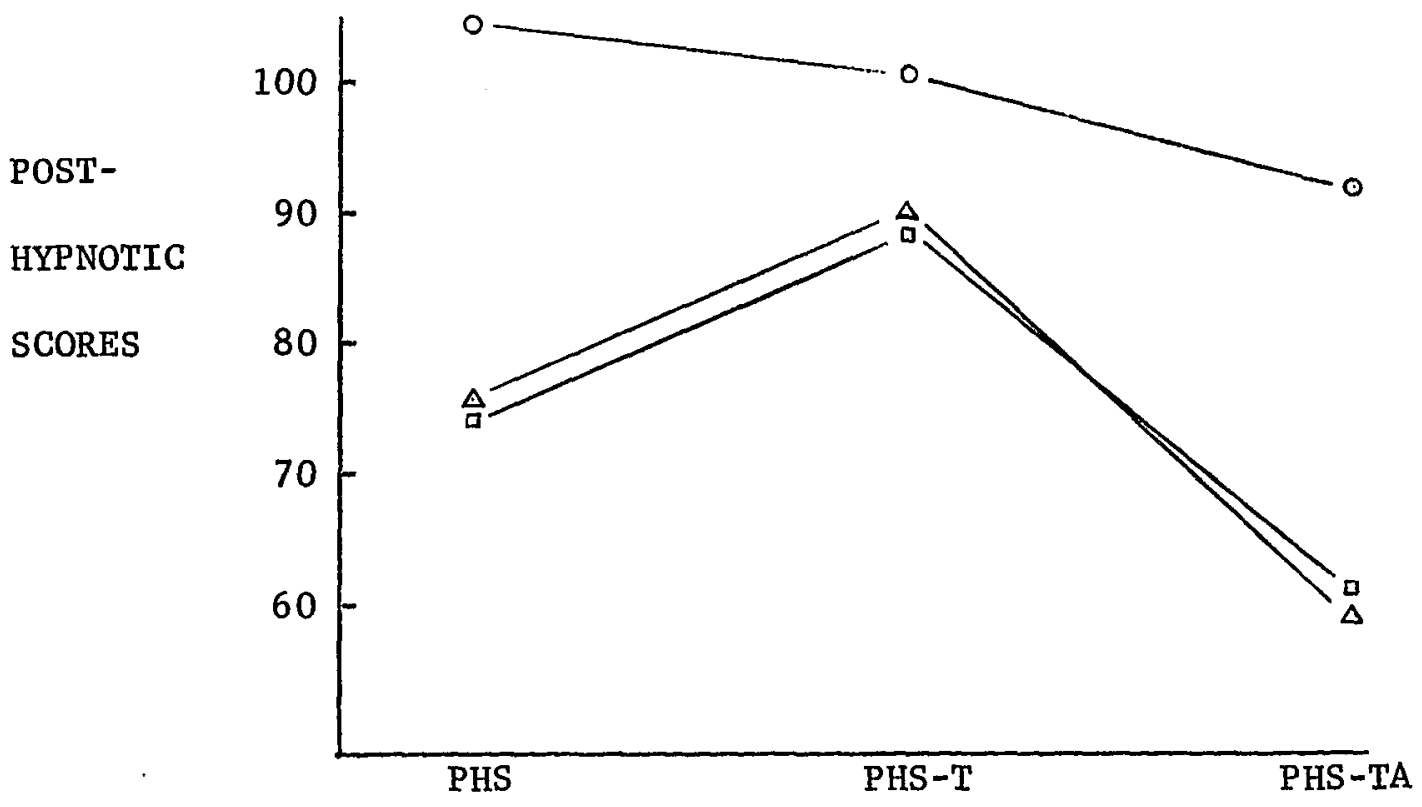
$\mathrm{N}$
口
$\boldsymbol{D}$
$\mathrm{RE}-\Delta \longrightarrow \Delta$
$R E+0 \longrightarrow$ o 


\section{DISCUSSION}

Examination of performance of $\underline{S}$ s over I-E conditions indicates that $\underline{S} s^{\prime}$ responses to the posthypnotic suggestion were apparently determined largely by expectations they had. $N$ and $R E-\subseteq s$ responded to the suggestion almost identically on an average for each $P-S$ condition. $\mathrm{RE}-\underline{\mathrm{S}} \mathrm{s}$, of course, were given the expectation that they would not be able to resist the posthypnotic suggestion. Why did they perform so identically with $\mathrm{N}$ S s who were given no instructions or expectations? It is likely that $N$ Ss probably came to the experiment with the expectation that they would conform to whatever suggestions were given them. That people generally have many such prior expectations about hypnosis has been demonstrated by Dorcus, Brintna11, and Case (1941), and London (1961). It is reasonable to conclude that both RE- and $N \underline{S} s$ had similar expectations which would account for their similar performances. It is surprising that RE- $\underline{S} s$, given instructions to resist the suggestion, performed no better on the Digit Symbol test than did N $\underline{S} s$. Apparently, $\underline{S} s^{\prime}$ expectations were much more important in influencing $\underline{S} s^{\prime}$ behavior than were the instructions to resist. These instructions under conditions of negative expectation appeared to have extremely little or no effect.

RE+ Ss performed about the same or improved on the second administration of the Digit Symbol test with the exception of 3 Ss

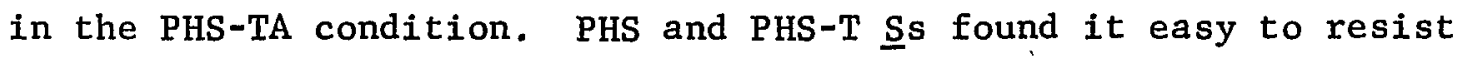


the suggestion when given the expectation that they could. The 3 PHS-TA $\underline{\text { S }}$ who had difficulty in resisting the suggestion will be discussed below.

It is interesting to note that RE+ and RE- $\underline{S} s$ did not consider the expectations they were given by $\underline{E}_{1}$ as part of the experiment. When $\underline{E}_{2}$ asked each $\underline{S}$ at the conclusion of the experiment to tell him what $\underline{S}$ was told prior to the experiment by $\underline{E}_{1}$, no $\underline{S}$ reported that an expectation had been communicated to her. They told $\underline{E}_{2}$ only of the instructions to resist the posthypnotic suggestion. When specifically asked about expectations, many $\underline{S}$ were temporarily confused as to what $\underline{E}_{2}$ wanted to know. Almost all $\underline{S}$ s were eventually able to verbalize that they had expectations congruent to those communicated by $\underline{E}_{1}$.

A general conclusion that follows from the above discussion is that $\underline{S}$ senerally respond to posthypnotic suggestions in a manner congruent with their prior expectations of how they will respond to such suggestions.

Ss' response to the posthypnotic suggestion also varied depending on the P-S condition to which they had been assigned. PHS-TA Ss responded significantly more to the suggestion than other P-S Ss in both $N$ and RE- conditions. Three PHS-TA $\underline{S}$ s in the RE+ condition also deteriorated on their second test performance, although the average score for the whole group just failed to be significantly different from the other RE+ groups. However, these $3 \underline{S}$ s were the only $R E+\underline{S} s$ to markedly decrease in performance. The largest score decrease in test performance by any of the other RE+ $\underline{S}$ s was 4 , 
whereas these $3 \underline{s}$ s decreased their scores by 8,21 , and 21 .

Ss who reported amnesia were clearly more responsive to the suggestion than other $\underline{S}$ s wich may indicate that $\underline{S}$ seporting amnesia may feel more compelled to respond to suggestions. Results of the 3 $\mathrm{RE}+\underline{\mathrm{S}} \mathrm{s}$ who responded to the suggestion further indicated that responsiveness for such $\underline{\text { S }}$ may not be totally influenced by their prior expectations. Whether or not these $\underline{S} s$ go into a deeper trance state or whether they just find it easier to enact or empathize with a role may only be a matter of semantics.

Surprisingly, PHS $\underline{S}$ s responded significantly more to the posthypnotic suggestion than PHS-T Ss with the exception of the RE+ condition, in which $\underline{S}$ s in both $\mathrm{P}-\mathrm{S}$ groups were able to resist the suggestion. It is important to note that $\underline{S}$ s in both PHS and PHS-T groups had shown the same levels of hypnotic susceptibility in previous training sessions. There were only 2 ss in the PHS group who had reported amnesia in the training sessions. Thus, differences between PHS and PHS-T groups cannot be explained in terms of any correlation that may exist between Ss reporting amnesia and responsiveness to suggestions.

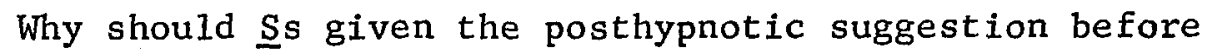
hypnotic induction respond more than $\underline{S}$ who received the suggestion following induction? These results certainly cannot be explained in terms of a trance effect. An expectational explanation seems more adequate. Ss in the PHS-T group were given a suggestion for amnesia concerning trance events. However, these $\underline{S}$ seported no amnesia. 
Their memory of trance events had contradicted the suggestion for amnesia given during trance. Their awareness of this contradiction may have served to weaken their expectations regarding effectiveness of suggestions in general. Ss in the PHS group had none of their expectations contradicted, and hence responded more to the suggestion although they did not receive it during trance. The fact that the PHS Ss were hypnotized following the suggestion defined the situation that they were in as one in which hypnosis was involved. This probably gave potency to their expectations regarding their inability to resist the suggestion, an expectation that they may not have acquired had they never been hypnotized.

If the above explanation is correct, $\underline{S}$ s do not appear to consciously plan to act out a role. If such were the case, it would be reasonable to expect that a 11 good hypnotic $\underline{S}$ sho responded to the posthypnotic suggestion would have also complied with the suggestion that they would be amnesic. That they should comply with one suggestion but not the other implies that $\underline{S} s$ do not have a clear awareness of a role that they are going to play during hypnosis. simulating hypnosis have previously been found to claim total amnesia for trance events whereas hypnotic $\underline{S} s$ under the same conditions often claimed only partial amnesia (Williamsen, Johnson, and Erikson, 1965). Some of the $\underline{S} s^{\prime}$ verbalizations about their experiences further suggest that they do not plan their hypnotic experiences. Following the Digit Symbol test, one $\mathrm{RE}-\underline{\mathrm{S}}$ who reported amnesia remarked that she had been sure that she would be able to resist the 
suggestion. She could not even pick up the pencil to begin the test! Some $N$ and RE- Ss voiced surprise that they were responding to the suggestion. One $\underline{S}$ insisted that she did as well as the first time on the test, although her second performance was far inferior to her first .

Almost a $11 \mathrm{~N}$ and $\mathrm{RE}-\underline{\mathrm{S}} \mathrm{s}$ reported strange or stiff feelings in their hand or arm, and difficulty in concentrating while taking the test following the posthypnotic suggestion. Many of these $\underline{\text { s }}$ became restless and appeared bewildered while taking the test. In contrast $\mathrm{RE}+\underline{\mathrm{S}} \mathrm{s}$ took the test rather matter of factly. A few of them reported some initial sensations in their hands which, they said, quickly disappeared. Notable exceptions were the 3 PHS-TA $\underline{S}$ s who responded to the suggestion.

A11 Ss in the experiment reported believing what was told to them by $\underline{E}_{1}$ and $\underline{E}_{2}$. None of the $\underline{S}$ s reported that they had discovered the rationale behind the experiment.

It is logical to conclude that what happens during hypnosis can perhaps best be conceptualized under the role enactment conception of Sarbin and Anderson (1967). Role enactment connotes involvement, commitment, and seriousness. It is not simply just acting out a role as usually conceptualized. $\underline{S}$ to some extent experiences the roles that he enacts. This enactment is perceived as genuine and real by $\underline{\mathbf{S}}$.

The likelihood that $\underline{S}$ will enact a role depends almost wholly on what expectations he has had regarding his assumption of the role. The expectations he harbors may come from any number of varied sources 
such as books, movies, etc., the hypnotist being only one such source. S may be only partially aware of what his expectations are.

The $\underline{S}$ who reports amnesia may actually feel that he is amnesic because of superior ability to enact roles. Prior expectations may be of lesser importance in influencing responsiveness to suggestions for these $\underline{S}$.

The trance concept may be unnecessary. S's knowledge that he is hypnotized may increase his responsiveness to suggestions only because of the expectancies associated with entering a trance. $\underline{S}^{\prime} s$ task motivation may also be highest under such conditions. All the so-called trance-like behaviors may be only responses to suggestions in the hypnotic induction procedure itse1f, and to prior expectations of what trance-1ike behavior should be like. If a trance per se has any effect on responsiveness, it must be trivial when compared to the influence of expectancies as illustrated by the greater responsiveness of the PHS group over the PHS-T group.

Future research should seek to establish whether $\underline{S} s$ reporting amnesia for trance events are more deeply involved than the usual $\underline{S}$ in enacting a role, or whether they go to greater lengths in attempting to please $\underline{E}$ by complying with his suggestions. Each $\underline{S}$ 's responsiveness to posthypnotic suggestions can be compared under conditions of both suggested amnesia and suggested non-amnesia, each $\underline{S}$ serving as his own control.

The question of whether there is a trance state that heightens $\underline{S}$ responsiveness to suggestions can also be more directly investigated 
by having $\underline{S}$ serve as his own control. Responsiveness of the same $\underline{S}$ can be compared in conditions where the posthypnotic suggestion is given directly before or after trance induction. 


\section{SUMMARY}

The present study sought to determine the role of expectation, amnesia, and hypnotic induction in the performance of posthypnotic behavior. Some Ss were instructed to resist a posthypnotic suggestion along with either a positive or negative expectation that they would be successful in resisting the suggestion. Other ss were not given any instructions or expectations regarding the posthypnotic suggestion. Ss were given the suggestion either immediately before or after a hypnotic induction. Ss given the suggestion during hypnosis also differed as to whether or not they reported amnesia for it.

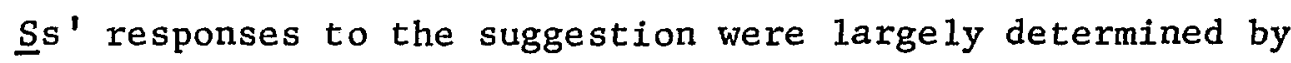
what expectations they had regarding their ability or inability to resist the suggestion. Ss reporting amnesia were more responsive to the suggestion. Whether or not Ss received the suggestion during trance appeared to be of little importance. SS' responsiveness to suggestions was explained in terms of role enactment. 


\section{REFERENCES}

Anderson, M. \& Sarbin, T. R. Base rate expectancies and motoric alterations in hypnosis. International Journal of Clinica1 and Experimenta 1 Hypnosis, $1964,12,147-156$.

Barber, T.X. Physiological effects of "hypnosis." Psychologica1 Bulletin, $1961,58,390-419$.

Barber, T. X. Experimental controls and the phenomena of "hypnosis": A critique of hypnotic research methodology. Journal of Nervous and Mental Disease, 1962, 134, 493-505. (a)

Barber, T.X. Toward a theory of hypnosis: Posthypnotic behavior. Archives of General Psychiatry, 1962, 7, 321-342.

Barber, T. X. The effects of "hypnosis" on pain: A critical review of experimental and clinical findings. Psychosomatic Medicine, $1963,25,303-333$.

Barber, T. X. "Hypnosis" as a causal variable in present-day psychology: A critical analysis. Psychological Reports, $1964,14,839-842$. (a)

Barber, T. X. Hypnotic "colorblindedness," "blindness," and "deafness." Diseases of the Nervous System, 1964, 25, 529-537.

(b)

Barber, T.X. An empirically-based formulation of hypnotism. American Journa1 of Clinica1 Hypnosis, $1969,12,100-130$.

Barber, T.X. Hypnosis: A scientific approach. Princeton, New Jersey: Van Nostrand, 1969. (b)

Barber, T.X., \& Calverley, D. S. "Hypnotic behavior" as a function of task motivation. Journal of Psychology, 1962, 54, 363-389.

Barber, T.X., \& Calverley, D. S. The relative effectiveness of task motivating instructions and trance induction procedure in the production of "hypnotic-like" behaviors. Journal of Nervous and Menta1 Disease, 1963, 137, 107-116. (a)

Barber, T. X., \& Calverley, D. S. Toward a theory of hypnotic behavior: Effects on suggestibility of task motivating instructions and attitudes toward hypnosis. Journal of Abnorma1 and Socia1 Psychology, 1963, 67, 557-565. (b) 
Barber, T. X., \& Calverley, D. S. An experimental study of "hypnotic" (auditory and visua1) hallucinations. Journal of Abnorma 1 and Social Psychology, 1964, 63, 13-20. (a)

Barber, T.X., \& Calverley, D. S. Experimental studies of "hypnotic" behavior: Suggested deafness evaluated by delayed auditory feedback. British Journal of Psychology, 1964, 55, 439-446. (b)

Barber, T.X., \& Calverley, D. S. Toward a theory of "hypnotic" behavior: An experimental study of "hypnotic time distortion." Archives of Genera1 Psychiatry, 1964, 10, 209-216. (c)

Barber, T. X., \& Calverley, D. S. Toward a theory of hypnotic behavior: Effects on suggestibility of defining the situation as hypnosis and defining response to suggestions as easy. Journa1 of Abnormal and Social Psychology, 1964, 68, 585-592. (d)

Barber, T. X., \& Calverley, D. S. Empirical evidence for a theory of "hypnotic" behavior: Effects of pretest instructions on response to primary suggestions. Psychological Record, 1964, $14,457-467$. (e)

Barber, T.X., \& Calverley, D. S. Comparative effects on "hypnoticlike" suggestibility of recorded and spoken suggestions. Journa1 of Consulting Psychology, 1964, 28, 384 .

Barber, T. X., \& Calverley, D. S. Empirical evidence for a theory of "hypnotic" behavior: Effects on suggestibility of five variables typically included in hypnotic induction procedures. Journal of Consulting Psychology, 1965, 29, 98-107. (a)

Barber, T.X., \& Calverley, D. S. Empirical evidence for a theory of "hypnotic" behavior: The suggestibility-enhancing effects of motivational suggestions, relaxation-sleep suggestions, and suggestions that the $\mathrm{S}$ will be effectively "hypnotized." Journa 1 of Personality, 1965, 33, 256-270. (b)

Barber, T. X., \& Calverley, D. S. Toward a theory of hypnotic behavior: Experimental evaluation of Hull's postulate that hypnotic susceptibility is a habit phenomenon. Journal of Personality, $1966,34,416-433$. (a)

Barber, T. X., \& Calverley, D. S. Toward a theory of "hypnotic" behavior: Experimental analyses of suggested amnesia. Journal of Abnorma 1 Psychology, 1966, 71, 95-107. (b) 
Barber, T. X., \& Calverley, D. S. Toward a theory of "hypnotic" behavior: Replication and extension of experiments by Barber and co-workers (1962-65) and Hilgard and Tart (1966). International Journal of clinical and Experimental Hypnosis, $1968,16,179-195$.

Barber, T. X., \& Calverley, D. S. Multidimensional analysis of "hypnotic" behavior. Journal of Abnorma1 Psychology, 1969, $74,209-220$.

Barber, T. X., Dala1, A. S., \& Calverley, D. S. The subjective reports of hypnotic subjects. American Journal of Clinical Hypnosis, 1968, 11, 74-88.

Barber, T. X., \& Deeley, D. C. Experimental evidence for a theory of hypnotic behavior: I. "Hypnotic colorblindness" without "hypnosia." International Journa1 of Clinical and Experimenta 1 Hypnosis, $1961,9,79-86$.

Barber, T. X., \& Glass, L. B. Significant factors in hypnotic behavior. Journal of Abnorma 1 and Social Psychology, 1962, $64,222-228$.

Barber, T. X., \& Hahn, K. W., Jr. Physiological and subjective responses to pain producing stimulation under hypnoticallysuggested and waking-imagined "analgesia." Journal of Abnorma 1 and Socia1 Psychology, $1962,65,411-418$.

Barber, T. X., \& Silver, M. J. Fact, fiction, and the experimenter bias effect. Psychologica1 Bulletin, 1968, (Monograph, Vol. 70, No. 6, Pt. 2, 1-29).

Bowers, K. S. Hypnotic behavior: The differentiation of trance and demand characteristic variables. Journal of Abnormal and Social Psychology, 1966, 71, 42-51.

Bowers, K. S. The effect of demands for honesty on reports of visual and auditory hallucinations. International Journal of clinical and Experimenta1 Hypnosis, $1967,15,31-36$.

Chaves, J. F. Hypnosis reconceptualized: An overview of Barber's theoretical and empirical work. Psychological Reports, 1968, $22,587-608$.

Coe, W. C., \& Sarbin, T. R. An experimental demonstration of hypnosis as role enactment. Journal of Abnorma 1 Psychology, 1966, 71, 400-406. 
Cooper, L. M. Spontaneous and suggested source amnesia. Internationa1 Journal of Clinical and Experimental Hypnosis, $1966,14,180-$ 193.

Crasilneck, M. B., \& Ha11, J. A. Physiological changes associated with hypnosis: A review of the literature since 1948 . International Journal of Clinical and Experimental Hypnosis, $1959,7,9-50$.

Dawson, Joseph G. Personal communication, 1970.

Deckert, G. H., \& West, L. J. Hypnosis and experimental psychopathology. American Journa 1 of Clinical Hypnosis, $1963,5,256-276$.

Derman, D., \& London P. Correlates of hypnotic susceptibility. Journal of Consulting Psychology, 1965, 29, 537-545.

Dorcus, R. M., Brintna11, A. K., \& Case, H. W. Control experiments and their relation to theories of hypnotism. Journal of

Genera 1 Psychology, 1941, 24, 217-221.

Dudley, D. C., Holmes, T. H., Martin, C. J., \& Ripley, H. S. Hypnotically induced facsimile of pain. Archives of General Psychiatry, 1966, 15, 198-204.

Edmonston, W. E.,Jr. Stimulus-response theory of hypnosis. In J.E. Gord on (Ed.), Handbook of clinical and experimental hypnosis. New York: Macmillan, 1967 . Pp. 345-387.

Edmonston, W. E.,Jr. Hypnosis and electrodermal responses. American Journal of Clinical Hypnosis, $1968,11,16-25$.

Edmonston, W. E.,Jr., \& Robertson, T. G., Jr. A comparison of the effects of task motivational and hypnotic induction instructions on responsiveness to hypnotic suggestibility scales. American Journa1 of Clinical Hypnosis, 1967, 9, 184-187.

Edward, G. Motivation and post-hypnotic effect. British Journa1 of Psychiatry, 1965, 111, 983-992.

Erickson, M. H., \& Erickson, E. M. Concerning the nature and character of post-hypnotic behavior. Journa1 of Psychology, $1941,24,95-133$.

Estabrooks, G. H. Hypnotism. New York: E. P. Dutton, 1943.

Evans, F. J. Recent trends in experimental hypnosis. Behavioral Science, $1968,13,477-487$. 
Fisher, S. The role of expectancy in the performance of posthypnotic behavior. Journal of Abnormal and Social Psychology, 1954, $49,503-507$.

Fisher, S. An investigation of alleged conditioning phenomena under hypnosis. Journa1 of Clinica1 and Experimenta1 Hypnosis, 1955, $3,71-103$.

Gi11, M. M., \& Brenman, M. Hypnosis and related states. New York: International Universities Press, 1961.

Graham, K. R. \& Patton, A. Retroactive inhibition, hypnosis, and hypnotic amnesia. Internationa1 Journal of clinical and Experimental Hypnosis, 1968, 16, 68-74.

Hartman, B. J. Hypnotizability as affected by attitudinal and motivational variables. International Journal of Clinical and Experimenta1 Hypnosis, 1967, 15, 86-91.

Hilgard, E. R. The motivational relevance of hypnosis. In M. R. Jones (Ed.), Nebraska Symposium on motivation. Lincoln, Nebraska: University of Nebraska Press, 1964, Pp. 1-40.

Hilgard, E. R. Hypnotic Susceptibility. New York: Harcourt, Brace, and Wor $1 \mathrm{~d}, 1965$.

Hilgard, E. R. Posthypnotic amnesia: Experiments and theory. International Journa1 of Clinical and Experimenta1 Hypnosis, $1966,14,104-111$.

Hilgard, E. R. \& Cooper, L。M. Spontaneous and suggested posthypnotic amnesia. International Journal of Clinical and Experimental Hypnosis, 1965, 13, 261-273.

Hilgard, E。 R. \& Tart, C. I' Responsiveness to suggestions following waking and imagination instructions and following induction of hypnosis. Journal of Abnormal Psychology, 1966, 71, 196-208.

Hoskovec, J., Svorad, D., \& Lanc, 0. The comparative effectiveness of spoken and tape-recorded suggestions of body sway. Internationa 1 Journal of Clinical and Experimenta1 Hypnosis, 1963, 11 , 163-166.

Hu11, C. L. Hypnosis and suggestibility: An experimental approach. New York: Appleton-Century-Crofts, 1933.

Klopp, K. K. Production of loca1 anesthesia using waking suggestion with the child patient. International Journal of Clinical and Experimenta1 Hypnosis, $1961,9,59-62$. 
Kramer, E. \& Tucker, G. R. Hypnotica11y suggested deafness and delayed auditory feedback. International Journal of Clinical and Experimenta1 Hypnosis, $1967,15,37-43$.

Le Cron, L. M., \& Bordeaux, J. Hypnotism today. New York: Grune and Stratton, 1949.

Levitt, E. E., \& Brady, J. P. Psychophysiology of hypnosis. In J. V. Schneck ( $\left.E d_{0}\right)$, Hypnosis in modern medicine (3rd ed.). Springfie1d, I11。: Thomas, 1963, Pp. 314-362.

London, P. Subject characteristics in hypnosis research: I. A survey of experience, interest, and opinion. International Journa1 of Clinical and Experimental Hypnosis, 1961, 9, 151-161.

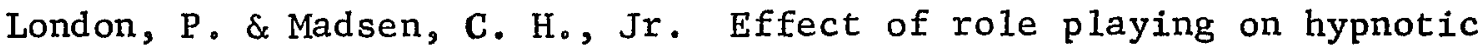
susceptibility in children. Journal of Personality and Socia1 Psychology, 1968, 10, 66-88.

Melei, J. P., \& Hilgard, E. R。 Attitudes toward hypnosis, selfpredictions, and hypnotic susceptibility. International Journa1 of Clinica1 and Experimental Hypnosis, 1964, 12, 99-108.

Orne, M. T. The nature of hypnosis: Artifact and essence. Journa1 of Abnorma 1 and Socia1 Psychology, 1959, 58, 277-299.

Orne, M. T. On the social psychology of the psychological experiment: With particular reference to demand characteristics and their implications. American Psychologist, 1962, 17, 776-783.

Orne, M. T. On the mechanisms of posthypnotic amnesia. International Journa1 of Clinica1 and Experimenta1 Hypnosis, 1966, 14, 121-134.

Orne, M. T. \& Evans, F. J. Social control in the psychological experiment: Antisocia1 behavior and hypnosis. Journal of Personality. and Socia1 Psychology, 1965, 1, 189-200.

Orne, M. T'. \& Evans, F.J. Inadvertant termination of hypnosis with hypnotized and simulating subjects. International Journal of Glinical and Experimental Hypnosis, $1966,14,61-78$.

Orne, M. T., Sheehan, P. W., \& Evans, F。 J. Occurrence of posthypnotic behavior outside the experimental setting. Journal of Personality and Social Psychology, 1968, 9, 189-196.

Overly, T. M., \& Levitt, E. E. A test of the expected homogeneity of simulator performance. International Journal of Clinical and Experimenta 1 Hypnosis, 1968, 16, 229-236. 
Pattie, F. A. A brief history of hypnotism. In J. E. Gordon (Ed.), Handbook of clinica1 and experimenta 1 hypnosis. New York: Macmi11an, 1967. Pp. 10-43.

Rosenthal, R. Experimenter expectancy and the reassuring nature of the nu11 hypothesis decision procedure. Psychological Bulletin, 1968, (Monograph, Vo1. 70, No. 6, Pt. 2, 30-47).

Sarbin, T. R., \& Anderson, M. L. Role-theoretical analysis of hypnotic behavior. In J. E. Gordon (Ed.), Handbook of clinical and experimental hypnosis. New York: Macmillan, 1967, Pp. 319-344.

Schneck, J. M. Observations on hypnotic dreams. Perceptual and Motor Ski11s, $1969,28,458$.

Sheehan, P. W. \& Orne, M. T. Some comments on the nature of posthypnotic behavior. Journal of Nervous and Mental Disease, $1968,146,209-220$.

Shor, R. E. Hypnosis and the concept of the generalized realityorientation. American Journa1 of Psychotherapy, 1959, 13, $582-602$.

Shor, R. E. Physiological effects of painful stimulation during hypnotic analgesia under conditions designed to minimize activity. International Journal of Clinical and Experimental Hypnosis, $1962,10,183-202$.

Shor, R. E., Orne, M. T., \& O'Conne11, D. N. Psychological correlates of plateau hypnotizability in a special volunteer sample. Journa1 of Persona1ity and Social Psychology, 1966, 3, 80-95.

Slotnick, R. S., Liebert, R. M., \& Hilgard, E. R. The enhancement of muscular performance in hypnosis through exhortation and involving instructions. Journal of Personality, 1965, 33, 37-45.

Slotnick, R. S. \& London, P. Influence of instructions on hypnotic and nonhypnotic performance. Journal of Abnormal and Social Psychology, 1965, 70, 38-46.

Sutcliffe, J. P. "Credulous" and "skeptical" views of hypnotic phenomena: A review of certain evidence and methodology. Internationa 1 Journal of Clinica1 and Experimenta1 Hypnosis, $1960,8,73-101$.

Sutcliffe, J. P. "Credulous" and "skeptical" views of hypnotic phenomena: Experiments in esthesia, hallucination, and delusion. Journal of Abnorma 1 and Social Psychology, 1961, $62,189-200$. 
Tart, C. T. \& Hilgard, E. R. Responsiveness to suggestions under "hypnosis" and "waking-imagination" conditions, a methodological observation. International Journal of Clinical and Experimenta1 Hypnosis, $1966,14,247-256$.

Thorne, D. E. Is the hypnotic trance necessary for performance of hypnotic phenomena? Journal of Abnormal Psychology, 1967, 72, 233-239.

Thorne, D. E., \& Beier, G. Hypnotist and manner of presentation effects on a standardized hypnotic susceptibility test. Journa1 of Consulting and Clinica1 Psychology, 1968, 32, 610-612.

Troffer, S. A. H., \& Tart, C. T. Experimenter bias in hypnotist performance. Science, 1964, 145, 1330-1331.

Wechsler, P. Manual for the Wechsler Adult Intelligence Scale. New York: Psychological Corporation, 1955.

Weitzenhoffer, A. M. \& Hilgard, E. R. Stanford Hypnotic Susceptibility Scale, Forms A and B. Palo Alto, California: Consulting Psychologists Press, 1959.

White, W. W. A preface to the theory of hypnotism. Journal of Abnorma 1 and Social Psychology, 1941, 36, 477-505.

Williamsen, J. A., Johnson, H. J., \& Eriksen, C. W. Some Characteristics of post-hypnotic amnesia. Journal of Abnorma1 Psychology, 1965, 70, 123-131.

Winer, B. J. Statistical principles in experimental design. New York: McGraw-Hi11, 1962.

Wolberg, L. R. Medical hypnosis. Vol. I: The principles of hypnotherapy. New York: Grune \& Stratton, 1948.

Young, P. C. Antisocial uses of hypnosis. In L. M. LeCron (Ed.), Experimental hypnosis. New York: Macmillan, 1952, Pp. 376-409.

Zamansky, H. S., Scharf, B., Brightbi11, R. The effect of expectancy for hypnosis on prehypnotic performance. Journa1 of Personality, 1964, 32, 236-248. 
APPENDIX A

SUBJECT SCREENING INSTRUMENTS 
HYPNOSIS SCREENING BATTERY

Name Phone

When available

Why did you volunteer?

Based on what you know and what you have heard about hypnosis, what do you think you will experience when hypnotized?

Have you in the past had any severe medical problems? Any present chronic illness? (Inquire as to heart disorder, blood pressure, fainting spells, rheumatic or scarlet fever, brain damage.)

Have you ever been administered chemical anesthetics such as ether, sodium pentathol? Did you have any adverse effects such as struggling when going under, required repeated administrations before anesthetic could take effect, or afterwards severe nausea or headache?

Have you ever sought psychiatric help?

Do you tend to be a nervous person?

Have you ever had thoughts you were ashamed of?

Have you smoked pot, taken ISD, pills such as barbituates or amphetamines, or any drug considered to be hallucinogenic? (Determine frequency, if yes.)

Have you ever had prolonged periods of being depressed?

Have you ever been robbed of your thoughts?

Are you often moody, tend to have ups and downs, days you just feel "down in the dumps?"

Do you find it very easy to become so completely absorbed in a book or a movie you like that you become unaware of what's going on around you? 
Do you like (do you think you would like) flying in an airplane? What, in particular, could scare you about flying? Is it (would it be) easy for you to trust the pilot? 
ITEMS IN THE STANFORD HYPNOTIC SUSCEPTIBILITY SCALE, FORMS A AND B (WEITZENHOFFER AND HILGARD, 1959)

\begin{tabular}{|c|c|c|c|}
\hline Item & Form A & Form B & Criterion of passing \\
\hline 1. Postural sway & Backwards & Backwards & Falls without forcing \\
\hline 2. Eye closure & $\begin{array}{l}\text { Form A } \\
\quad \text { induction }\end{array}$ & $\begin{array}{l}\text { Form } B \\
\quad \text { induction }\end{array}$ & $\begin{array}{l}\text { Eyes close without } \\
\text { forcing }\end{array}$ \\
\hline 3. Hand lowering & Left & Right & $\begin{array}{l}\text { Lowers at least } 6 \\
\text { inches by end of } 10 \\
\text { seconds }\end{array}$ \\
\hline 4. Arm immobilization & Right arm & Left arm & $\begin{array}{c}\text { Arm rises less than } 1 \\
\text { inch in } 10 \text { seconds }\end{array}$ \\
\hline 5. Finger lock & Before chest & Overhead & $\begin{array}{l}\text { Incomplete separation } \\
\text { of fingers at end of } \\
10 \mathrm{sec} \text {. }\end{array}$ \\
\hline 6. Arm rigidity & Left arm & Right arm & $\begin{array}{l}\text { Less than } 2 \text { inches of } \\
\text { arm bending in } 10 \\
\text { seconds }\end{array}$ \\
\hline 7. Moving hands & Together & Apart & $\begin{array}{l}\text { (A) Hands close as } 6 \\
\text { inches } \\
\text { (B) Hands apart at } \\
\text { least } 6 \text { inches }\end{array}$ \\
\hline 8. Verbal inhibition & Name & Home town & $\begin{array}{l}\text { Name unspoken in } 10 \\
\text { seconds }\end{array}$ \\
\hline 9. Hallucination & F1y & Mosquito & $\begin{array}{l}\text { Any movement, grimacing } \\
\text { acknowledgment of } \\
\text { effect }\end{array}$ \\
\hline 10. Eye catalepsy & $\begin{array}{c}\text { Both eyes } \\
\text { closed }\end{array}$ & $\begin{array}{c}\text { Both eyes } \\
\text { closed }\end{array}$ & $\begin{array}{l}\text { Eyes remain closed at } \\
\text { end of } 10 \text { seconds }\end{array}$ \\
\hline 11. Posthypnotic & Changes chairs & $\begin{array}{l}\text { Rises, } \\
\quad \text { stretches }\end{array}$ & $\begin{array}{l}\text { Any partial movement } \\
\text { response at signa } 1\end{array}$ \\
\hline 12. Amnesia & $\begin{array}{l}\text { Reca } 11 \text { of } \\
\text { items } 3-11\end{array}$ & $\begin{array}{l}\text { Reca } 11 \text { of } \\
\text { items } 3-11\end{array}$ & $\begin{array}{l}\text { Recal1 of three or } \\
\text { fewer items }\end{array}$ \\
\hline
\end{tabular}


Technical Data on SHSS

The SHSS has been standardized at Stanford and has been shown to be a reliable instrument (Hilgard, 1965). The mean items passed by 533 stanford students was 5.62 with a standard deviation of 3.27 . Retest reliabilities using different hypnotists and alternate forms over two days of testing ranged from .91 to .95 for different samples. 
APPENDIX B

PRE-TRANCE-INDUCTION INSTRUCTIONS 


\section{REt Instructions}

Listen very carefully to the instructions that I'm about to give you and if you have any questions about the instructions be sure and ask them. When I finish the instructions, I'11 give you a chance to ask any questions you may have. In a while you are going to be hypnotized by Mr. Gandolfo. Mr. Gandolfo will give you a suggestion while you're in the trance to do something posthypnotically after you are awakened from your trance. What I want you to do is to resist performing this posthypnotic act. I do not want you to resist going into a trance or listening to the posthypnotic suggestion. I only want you to resist performing the posthypnotic act after you are awakened. (E) then urged $\underline{S}$ to ask any questions if she had any. $\underline{E}_{1}$ did not give any answers that indicated anything further about the experiment. After this, $\underline{E}_{1}$ said the following in a very casual and "off the cuff" manner.) It's been rea11y interesting that all of our subjects have been able to resist performing the posthypnotic act so we're sure you will be able to resist also unless you're a really unusual subject. Mr. Gandolfo has the hypothesis that people can resist performing posthypnotic suggestions and fortunately his hypothesis has been we11 supported so far judging by previous subjects. By the way, in order to eliminate any bias on the part of Mr. Gandolfo, I do not want you to tell him that you are supposed to resist performing the posthypnotic suggestion. You see, some subjects are not told to resist, and Mr. Gandolfo does not know who's who. Also, don't 
discuss anything that we've discussed with any of the other subjects because it might effect their responses and thus the experiment. 


\section{$\underline{\mathrm{RE}-\text { Instructions }}$}

Listen very carefully to the instructions that I'm about to give you and if you have any questions about the instructions be sure and ask them. When I finish the instructions, I'11 give you a chance to ask any questions you may have. In a while you are going to be hypnotized by Mr. Gandolfo. Mr. Gandolfo will give you a suggestion while you're in the trance to do something posthypnotically after you are awakened from your trance. What I want you to do is to try to resist performing the posthypnotic act. I do not want you to resist going into a trance or listening to the posthypnotic suggestion. I only want you to try to resist performing the posthypnotic act after you are awakened. (E) then urged $\underline{\mathrm{S}}$ to ask any questions if she had any. $\underline{E}_{1}$ did not give any answers that indicated anything further about the experiment. After this, $\underline{E}_{1}$ said the following in a very casual and "off the cuff" manner.) It's been really interesting that none of our subjects have been able to resist performing the posthypnotic act so we're pretty sure that you won't be able to resist unless you're a really unusual subject. Mr. Gandolfo has the hypothesis that posthypnotic acts are compulsions that are irresistible. So far his hypothesis has been very well supported judging by oux prior subjects. By the way, in order to eliminate any bias on the part of Mr. Gandolfo, I do not want you to tel1 him that you are supposed to resist performing the posthypnotic suggestion. You see, some subjects are not told to resist, and Mr. Gandolfo does not know who's who. Also, don't 
discuss anything that we've discussed with any of the other subjects because it might effect their responses and thus the experiment. 


\section{APPENDIX C}

\section{THE POSTHYPNOTIC SUGGESTION}


The Posthypnotic Suggestion

If you remember, a while back, you took the Digit Symbol test. This was a test that had a number of boxes with numbers in the upper part, and spaces in the lower part. If you remember, you filled in the spaces below the numbers with the marks that should go there. We1l, you're going to take this test again, as a matter of fact, shortly after you are awakened. However, this time when you take the test, your hand, your writing hand, is going to undergo some strange experiences. It's going to feel very, very funny. Your writing hand is going to feel very, very stiff, very rigid. Your whole hand is going to feel very stiff and rigid. Your fingers are going to feel very, very stiff, very rigid. Your whole hand is going to feel very, very heavy. It's going to be very, very difficult for you to hold onto a pencil, because your hand will feel so stiff, your fingers so stiff and rigid. It will be very hard to write. You will wonder how you could possibly even pick up a pencil. You will find it extremely difficult to hold onto a pencil and to write. Your fingers are going to feel so stiff, they're going to feel so rigid. Your hands and your fingers are going to feel very stiff and very rigid. When you are told to take the Digit symbol test, your hand is going to undergo a11 these strange experiences. It's going to be very, very hard for you to take this test, very, very difficult, very difficult. As a matter of fact, you will have to go very slowly when you take this test. Otherwise, you will make too many mistakes. You will have to 
go very, very slowly. Your hand will feel very, very funny. Your fingers will feel so rigid, your hand will feel so heavy, the pencil will feel like a foreign object in youx hand. You will find it very, very difficult to take the test. You will be so worried about the way your hand feels that it will be difficult for you to concentrate on the test. Your hand will be a lot more important to you than taking the test. You will be worried about the way your hand feels, the way your fingers feel so stiff and so rigid, like pieces of wood. The way your hand is heavy, the way it is hard for you to hold onto a pencil, the way it is hard for you to write. You will be very worried about the way your hand feels, and you will not be able to concentrate very well on the test. You will have to go very slow on the test to avoid making mistakes, extremely slow. It'11 be very, very difficult for you to take the test. It will take you a long time to complete it. You will have to go very slowly and carefully, making sure you haven't made mistakes, making sure you can form the symbols. It will be very, very slow.

As soon as you finish taking the Digit symbol test, your hand will feel normal again. But while you are taking the test, your hand wil1 undergo these strange experiences and feel very, very funny. As soon as you have finished with the test, your hand will feel normal, but not until you've finished. While you are taking the test, your. hand will feel very strange, and very funny, and you will worry about it, and you will find that you will have to go very slowly on this test. 
VITA

Rona1d Lawrence Gandolfo was born October 29, 1942, in San Francisco, California and he grew up in San Mateo, California. He graduated from Serra high school, June, 1960, and spent the following two years at College of San Mateo. He received his B.A. degree from the University of California at Berkeley, June, 1964. The author spent one year at San Francisco State College before coming to Louisiana State University where he received his M.A. degree in psychology, August, 1967. The following year was spent at Napa State Hospital in Napa, California, where the author did his internship in clinical psychology.

The author published a study with Robert S. Schlottmann completed at the Louisiana State University Primate Laboratory titled, "Socia1 Isolation of Socially Sophisticated Java (Macaca irus) Monkeys." He married the former Ruth Fasoldt from Syracuse, New York. 
Candidate: Ronald Lawrence Gandolfo

Major Field: Psychology

Title of Thesis: The Role of Expectancy, Amnesia, and Hypnotic

Induction in the Performance of Posthypnotic Behavior.

Approved:

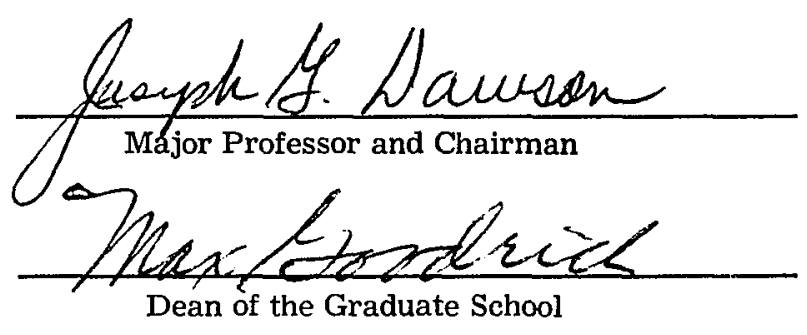

EXAMINING COMMITHEE:
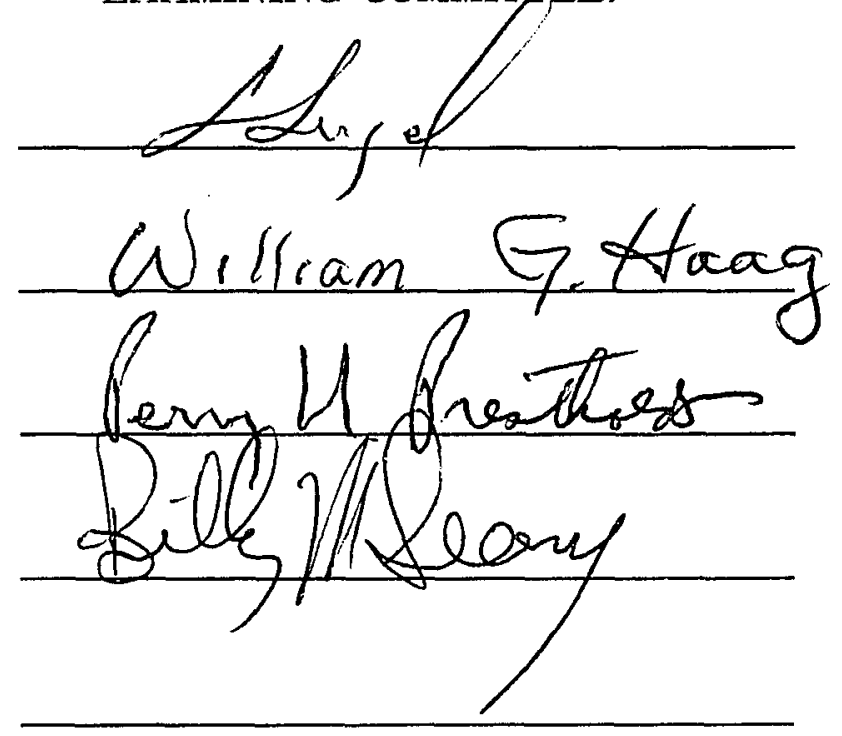

Date of Examination: 